This document is the Accepted Manuscript version of a Published Work that appeared in final form in Biomacromolecules, copyright (C) American Chemical Society after peer review and technical editing by the publisher. To access the final edited and published work see https://pubs.acs.org/doi/abs/10.1021/acs.biomac.0c00824.

\title{
Stabilizing Enzymes within Polymersomes by Co-Encapsulation of Trehalose
}

Maria Valentina Dinu, ${ }^{* 1,2}$ Ionel Adrian Dinu, ${ }^{1,2}$ Sina S. Saxer, ${ }^{3}$ Wolfgang Meier, ${ }^{1}$ Uwe Pieles, ${ }^{3}$ and Nico Bruns*4,5

${ }^{1}$ Department of Chemistry, University of Basel, Klingelbergstrasse 80, 4056 Basel, Switzerland.

${ }^{2}$ Department of Functional Polymers, "Petru Poni" Institute of Macromolecular Chemistry, Grigore Ghica Voda Alley 41 A, 700487 Iasi, Romania.

${ }^{3}$ Institute for Chemistry and Bioanalytics, School of Life Sciences, University of Applied Sciences and Arts Northwestern Switzerland, 4132 Muttenz, Switzerland.

${ }^{4}$ Adolphe Merkle Institute, University of Fribourg, Chemin des Verdiers 4, 1700 Fribourg, Switzerland.

${ }^{5}$ Department of Pure and Applied Chemistry, University of Strathclyde, Thomas Graham Building, 295 Cathedral Street, Glasgow G1 1XL, UK.

*E-mails: vdinu@icmpp.ro; nico.bruns@strath.ac.uk.

KEYWORDS: Polymersomes, Trehalose, Nanoreactors, Enzyme Stabilization, Lyoprotectants. 


\section{ABSTRACT}

Enzymes are essential biocatalysts and very attractive as therapeutics. However, their functionality is strictly related to their stability, which is significantly affected by the environmental changes occurring during their usage or long-term storage. Therefore, maintaining the activity of enzymes is essential when they are exposed to high temperature during usage, or when they are stored for extended periods of time. Here, we stabilize and protect enzymes by co-encapsulating them with trehalose into polymersomes. The anhydrobiotic disaccharide preserved up to about $81 \%$ of enzyme's original activity when laccase/trehalose-loaded nanoreactors were kept desiccated for 2 months at room temperature, and $75 \%$ of its activity when heated at $50{ }^{\circ} \mathrm{C}$ for 3 weeks. Moreover, the applicability of laccase/trehalose-loaded nanoreactors as catalysts for bleaching of the textile dyes Orange $\mathrm{G}$, Toluidine Blue $\mathrm{O}$ and Indigo was proven. Our results demonstrate the advantages of co-encapsulating trehalose within polymersomes to stabilize enzymes in dehydrated state for extended periods of time, preserving their activity even when heated to elevated temperature.

\section{INTRODUCTION}

The wide range of features presented by enzymes and other proteins makes them very attractive as therapeutics and selective biocatalysts in biomedical, industrial, chemical, and biotechnological applications $^{1}$. For example, laccases reduce a wide range of aromatic compounds, which makes them particularly useful for pulp bleaching in the paper industry ${ }^{2}$, decolourisation of textile dyes ${ }^{3}$, in biofuel cells ${ }^{4}$, as biosensors (for phenolic agents ${ }^{5}$ or catechol derivatives ${ }^{6}$ ), as environmental benign catalysts in synthesis ${ }^{1,2}$, and for 
bioremediation and detoxification of environmental pollutants ${ }^{1,2}$. However, the practical application of enzymes is often limited by the low stability of enzymes when stressed by desiccation, heat, light, high pressure or $\mathrm{pH}$ changes $^{7,8}$. Moreover, proteins denature over time even when they are stored as a powder ${ }^{7,8}$.

The addition of excipients (additives) is a common strategy to stabilize proteins under extreme conditions. Many additives, such as osmolytes (including sugars) $)^{8,9}$, polymers ${ }^{8,10}$, and salts ${ }^{8}$, have been reported to prevent denaturation of proteins. Alternative routes for protein stabilization include the encapsulation of enzymes in polymeric gels ${ }^{11}$, cross-linking of enzyme aggregates ${ }^{12}$, or immobilization on solid supports ${ }^{13}$. Nevertheless, a significant loss in activity is often observed in aqueous environments for the entrapped or immobilized enzyme, which could be attributed to either a decreased conformational flexibility of the enzyme when constrained within the support matrix and/or mass transport limitations for substrates and products ${ }^{13}$. In addition, an increased thermal stability and extended protein lifetime is often required for a wide range of biotechnological applications. Therefore, maintaining high levels of enzyme activity after protein immobilization remains an ongoing challenge.

To improve biocatalytic activity and stability, the entrapment of enzymes within microcapsules ${ }^{14}$ and nanoflowers ${ }^{15}$ is a good choice as it can be done in mild processes that cause only relatively small changes to the native structure of the enzyme. Liposomes have also been used to protect enzymes ${ }^{16}$. However, their major disadvantage is that they can be unstable over time and leaky ${ }^{16}$. To overcome these issues, polymer vesicles, also termed polymersomes, have been investigated as protective compartments for enzymes because of their higher stability ${ }^{16}$. Moreover, the wide diversity of polymer chemistry offers the 
possibility to modulate the properties of polymersomes in terms of size, membrane flexibility, permeability, stimuli-responsiveness and decoration with functional ligands ${ }^{16-24}$. For example, the use of $\mathrm{pH}$-sensitive photo-cross-linkable copolymers allowed the chemical and mechanical tuning of membrane permeability leading to polymersomes which are stable at high shear rates, while the transport through their membrane is simply controlled by $\mathrm{pH}$ changes $^{18}$. To function as nanoscale reaction vessels, polymer vesicles should encapsulate catalytically active biomolecules within their cavity, and their membrane should allow the exchange of substrates between the outside and the inside of polymersomes ${ }^{16-18,25-33}$. In this context, the encapsulation of various enzymes into polymersomes has been demonstrated $^{26,28-32}$, and the permeabilization of polymersome membranes can be achieved by several strategies including reconstitution of membrane proteins ${ }^{17}$, use of block copolymers that form porous membranes ${ }^{28}$, emulsion polymerization-induced self-assembly technique ${ }^{26}$, or reaction of photoactive reagents with block copolymer membranes ${ }^{29,31,33}$. However, polymersomes themselves are often not stable enough, especially when the biocatalytic formulation must be dried for long-time storage or when they are used at elevated temperatures. Previous studies showed that the stability of polymersome membranes could be enhanced by cross-linking ${ }^{18,33,34}$. UV-triggered cross-linking allows the formation of hollow spherical architectures whose polymer membranes have an enhanced structural stability and robustness against mechanical shear forces ${ }^{34}$. But the stability of enzyme within polymersomes is still an unsolved problem. To avoid undesirable changes or possible damage of self-assembled nano-architectures upon storage in aqueous dispersion, and to prevent the denaturation of the loaded protein, the vesicles can be lyophilized ${ }^{7,35}$. One possibility to make the vesicles and their contents more stable during lyophilization is to add 
lyoprotectants during vesicle preparation or to polymersome dispersions ${ }^{36-38}$. A recent example involves the use of inulin as lyoprotectant to provide myoglobin-loaded polymersomes with adequate stability during cryogenic freezing and freeze-drying ${ }^{38}$.

In nature, microscopic animals named tardigrades or water bears protect themselves against the negative effect of various extremely adverse conditions by synthesizing a non-reducing disaccharide, trehalose. It protects their biomolecules from environmental stresses so that they can survive for long periods in drought conditions. They can recover full viability upon rehydration ${ }^{39,40}$, and even survive after exposure to vacuum and cosmic radiation of space ${ }^{41}$. Although trehalose is widely used as an additive for long-term preservation of therapeutic proteins, foods, and cosmetics, there is still much debate over the mechanism of trehalose stabilizing ability ${ }^{42-48}$. It appears that during desiccation or heating, the sugar molecules stabilize and protect biomolecules either by hydrogen bonding or by formation of an amorphous glass-like structure, concentrating around proteins and limiting the mobility of residual water at the protein surface. Thus, a hydration shell is permanently maintained at the protein surface by the trehalose glass, which acts as a lyoprotectant ${ }^{43}$.

Inspired by the protective mechanism of tardigrades, we hypothesize that trehalose, when co-encapsulated with enzymes into polymersome nanoreactors, could significantly enhance the stability of the enzymes. Here, we endow laccase from Trametes versicolor (Lac) and horseradish peroxidase (HRP) with a longer shelf-life and a better stability upon desiccation and heat, using enzyme/trehalose-loaded polymersome nanoreactors (Fig. 1). 


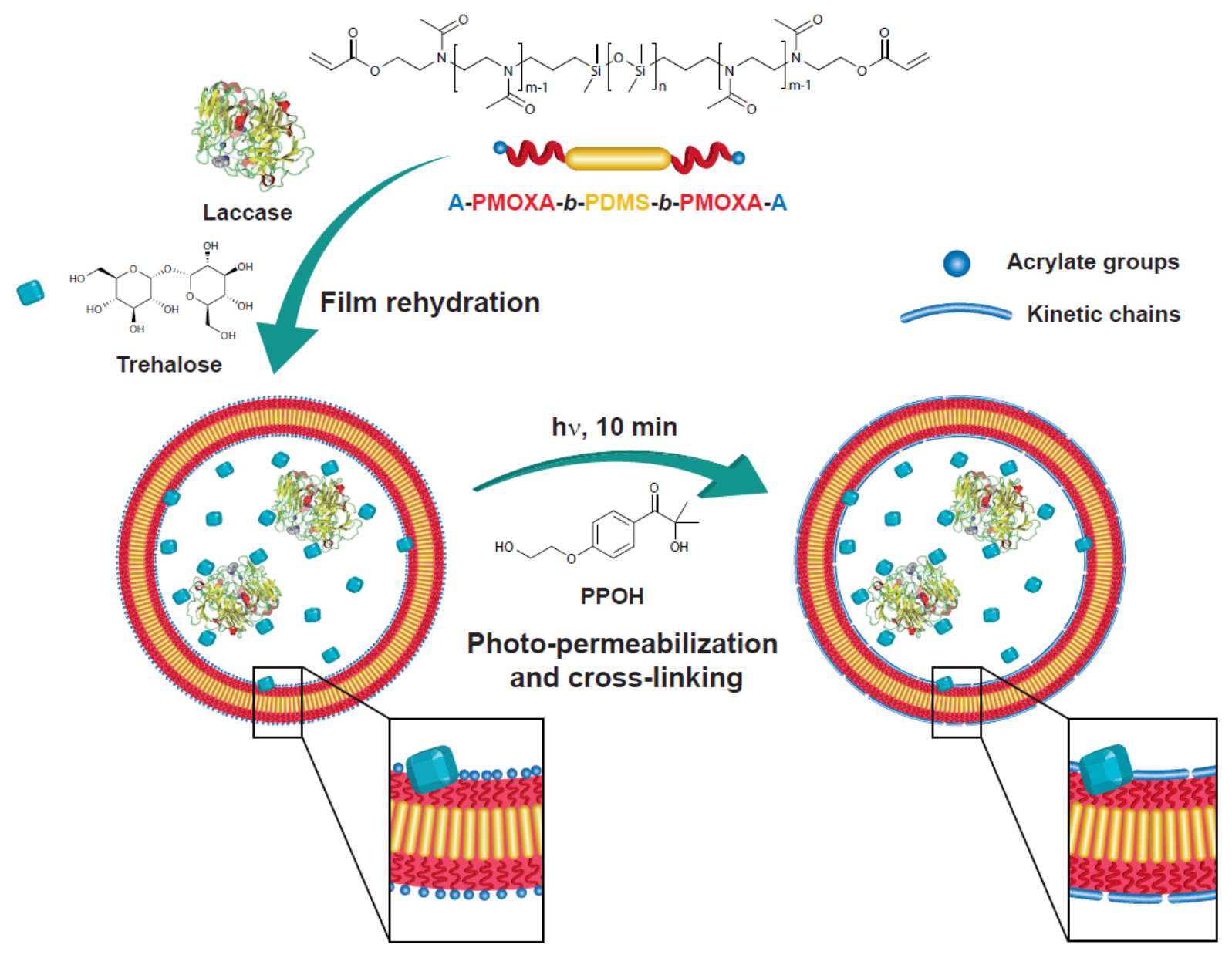

Fig. 1. Formation of trehalose-containing polymersome nanoreactors. The graphical representation depicts the whole process of co-encapsulation of enzyme and trehalose during vesicle formation, photo-induced permeabilization, and vinyl end group polymerisation. The amphiphilic block copolymer chains were self-assembled in the presence of laccase (or horseradish peroxidase) and trehalose yielding enzyme/trehalose-loaded vesicles, which were subsequently permeabilized and cross-linked by photoreaction with PPOH.

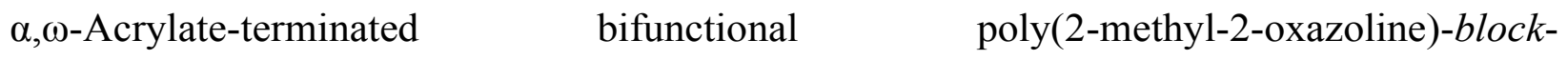
polydimethylsiloxane-block-poly(2-methyl-2-oxazoline) (PMOXA-b-PDMS- $b$-PMOXA) triblock copolymers were self-assembled into vesicular nanostructures in aqueous solutions 
containing trehalose and one of the enzymes. This resulted in the simultaneous encapsulation of the biocatalyst and the lyoprotectant within polymersomes during the process of vesicle formation. These polymersomes were turned into nanoreactors by UVinduced membrane permeabilization with 2-hydroxy-4'-2-(hydroxyethoxy)-2methylpropiophenone (PPOH) according to our previously reported protocol ${ }^{29,31}$. Moreover, polymersomes were stabilized by crosslinking using an excess of PPOH. The retention of protein functionality upon desiccation and the thermal stability of nanoreactors in dehydrated state were assessed as a function of the amount of encapsulated trehalose. Furthermore, the catalytic activity of laccase/trehalose-filled nanoreactors in the environmentally friendly oxidation of three textile dyes was investigated.

\section{EXPERIMENTAL}

\section{Materials}

$\alpha, \omega$-Bifunctional acrylate-terminated poly(2-methyl-2-oxazoline)- $b$-poly(dimethylsiloxane)$b$-poly(2-methyl-2-oxazoline) triblock copolymer (A-PMOXA ${ }_{19}-b$-PDMS $67-b$-PMOXA $\left.19-\mathrm{A}\right)$ (data from commercial provider: average number average molecular weight $\mathrm{M}_{\mathrm{n}}=8000 \mathrm{~g}$ $\mathrm{mol}^{-1}$, dispersity $Đ=1.3$ ) was purchased from Polymer Source (Quebec, Canada). The commercial copolymer was further purified by solvent extraction using a hexane/methanol mixture, as previously described ${ }^{49}$. The corresponding polymer fraction was recovered from the methanol phase after solvent removal using a rotary vacuum evaporator, then dispersed in MilliQ water, and finally lyophilized. After these additional steps, the copolymer was characterized by proton nuclear magnetic resonance ( $\left.{ }^{1} \mathrm{H}-\mathrm{NMR}\right)$ spectroscopy (Fig. S1) and size-exclusion chromatography (SEC), obtaining the final structure as A-PMOXA $15-b$ PDMS $_{60}-b$-PMOXA $15-A$ with $\mathrm{M}_{\mathrm{n}}=7500 \mathrm{~g} \mathrm{~mol}^{-1}$ (from ${ }^{1} \mathrm{H}-\mathrm{NMR}$ ) and $\mathrm{Ð}=1.4$ (from SEC). 
Lac (from Trametes versicolor, $\geq 10 \mathrm{U} \mathrm{mg}^{-1}, 1 \mathrm{U}$ corresponds to the amount of enzyme which converts $1 \mu \mathrm{mol}$ catechol per minute at $\mathrm{pH} 4.6$ and $25{ }^{\circ} \mathrm{C}$; Sigma-Aldrich) and HRP (320 $\mathrm{U} \mathrm{mg}^{-1}, 1 \mathrm{U}$ catalyzing the production of $1 \mathrm{mg}$ of purpurogallin from pyrogallol in 20 seconds at $20{ }^{\circ} \mathrm{C}$ and $\mathrm{pH}$ 6.0; Fisher Scientific) were purchased as lyophilized powders. Proteinase K (recombinant, PCR Grade, lyophilized from Pichia pastoris) was received from Roche Diagnostics. 2-Hydroxy-4'-(2-hydroxyethoxy)-2-methylpropiophenone (PPOH; ${ }^{1} \mathrm{H}-\mathrm{NMR}$ spectrum is shown in Fig. S2), 2,2'-azino-bis(3-ethylbenzothiazoline-6-sulfonic acid) diammonium salt (ABTS), D-(+)-trehalose (dehydrate from Saccharomyces cerevisiae, $\geq 99 \%$ ), glycerol, D-(+)-mannose ( $\geq 99 \%$ ), sodium acetate buffer $(\mathrm{pH} 4.6,222$ $\mathrm{mM}$ ), synthetic indigo (dye content 95\%), Orange G (dye content $80 \%$ ), Toluidine Blue O (dye content 80\%) and all the other chemicals were purchased from Sigma-Aldrich and used without further purification.

\section{Preparation of enzyme/additive-loaded polymersomes}

$2 \mathrm{~mL}$ of $4 \mathrm{mg} \mathrm{mL}^{-1}$ A-PMOXA $15-b$-PDMS $60-b-\mathrm{PMOXA}_{15}$-A solution in ethanol were added into a $5 \mathrm{~mL}$ round bottom flask. The solvent was slowly evaporated to dryness at reduced pressure to form a thin polymer film, using a rotary vacuum evaporator. Enzyme/additiveloaded vesicles were formed under gentle stirring for $24 \mathrm{~h}$, at room temperature (RT, $22^{\circ} \mathrm{C}$ ) by rehydration of the polymer film using $2 \mathrm{~mL}$ of sodium acetate buffer (pH 4.6) containing $2 \mathrm{mg} \mathrm{mL}^{-1}$ enzyme (Lac or HRP) and $0.5 \mathrm{mg} \mathrm{mL}^{-1}$ to $10 \mathrm{mg} \mathrm{mL}^{-1}$ of one of the following additives: glycerol, mannose, or trehalose. The aqueous vesicle dispersions were extruded 11 times through a Nucleopore track-etched polycarbonate membrane (MilliQ) with a pore size of $200 \mathrm{~nm}$ using an Avanti mini-extruder (Avanti Polar Lipids, USA) to obtain polymersomes of rather uniform size. Free enzyme and non-encapsulated additive were then 
removed during two consecutive purification steps. Size exclusion chromatography (SEC) was performed using a $20 \mathrm{~cm}^{3}$ in-house packed Sepharose 2B column $(60-200 \mu \mathrm{m}$ bead diameter, GE Healthcare). The first fraction, which contained the polymersomes, was collected and purified immediately by dialysis against acetate buffer at RT for 2 days (buffer exchanged every four hours during daytime), using $100 \mathrm{kDa}$ MWCO dialysis tubes (Spectra/Por Biotech-Grade CE Dialysis Tubing, 16mm/10mm, Spectrum Labs, Germany).

The final concentration of polymer was calculated as $2.66 \mathrm{mg} \mathrm{mL}^{-1}$, taking into consideration the dilution occurring during the SEC and dialysis, and assuming there was no loss of polymer during film rehydration, extrusion and purification.

\section{Preparation of enzyme-loaded polymersomes}

Enzyme-loaded vesicles without encapsulated additives were prepared as described above, but no additives were added to the enzyme solution during film rehydration.

\section{Permeabilization and stabilization of polymersome membrane}

All vesicle dispersions were bubbled with argon before UV exposure to remove oxygen. After the purification of polymersomes by SEC and dialysis, $\mathrm{PPOH}$ was added to $2 \mathrm{~mL}$ of polymersome dispersion to a final concentration of $1 \mathrm{mg} \mathrm{mL}^{-1}$. Then, the mixture was irradiated with UV light for $30 \mathrm{~s}, 60 \mathrm{~s}$ or $600 \mathrm{~s}$. The UV irradiation was performed using a Hamamatsu LC4 UV mercury/xenon lamp. The distance of each sample from the source was $5 \mathrm{~cm}$ and the wavelength band of $365 \mathrm{~nm}$ was isolated using optical filters ${ }^{50}$. The light intensity was $10 \mathrm{~mW} \mathrm{~cm}$-2 on each sample as measured with an OAI Model $308 \mathrm{UV}$ Intensity/Power Meter (S.P.S. Vertriebs GmbH, Germany). The samples were additionally purified by dialysis against acetate buffer ( $\mathrm{pH} 4.6)$ at $\mathrm{RT}$ for 1 day (buffer exchanged every four hours) to remove the unreacted $\mathrm{PPOH}$ before recording their ${ }^{1} \mathrm{H}-\mathrm{NMR}$ spectra and 
before using them in further experiments. To record the NMR spectra, the samples were dried under reduced pressure using a rotary evaporator, then transferred into $\mathrm{CDCl}_{3}$, and finally filtered (with the syringe filters typically used for preparation of SEC samples). The cross-linking of terminal vinyl groups was investigated by ${ }^{1} \mathrm{H}-\mathrm{NMR}$ spectroscopy. For comparison, $2 \mathrm{~mL}$ vesicle dispersions were also irradiated by UV-light in the absence of PPOH for $600 \mathrm{~s}$ or $900 \mathrm{~s}$ and analysed by ${ }^{1} \mathrm{H}-\mathrm{NMR}$ spectroscopy without further purification by dialysis.

\section{Enzyme encapsulation efficiency}

To determine the Lac concentration in all samples containing Lac-loaded polymersomes, the absorption at $330 \mathrm{~nm}$, which is characteristic for the T3 copper centre, was considered ${ }^{30,51}$. Because a different buffer was used than in our previous work, an extinction coefficient of $0.4 \times 10^{5} \mathrm{M}^{-1} \mathrm{~cm}^{-1}(330 \mathrm{~nm})$ was experimentally determined using a dilution series of Lac. The HRP concentration in all samples containing HRP-loaded polymersomes was determined by measuring the Soret absorption at $403 \mathrm{~nm}$, considering an extinction coefficient of $0.9 \times 10^{5} \mathrm{M}^{-1} \mathrm{~cm}^{-129}$. Accordingly, the concentration of Lac in Lac-loaded polymersomes was $0.36 \mathrm{mg} \mathrm{mL}^{-1}$, which corresponds to an encapsulation efficiency of $18 \%$ with respect to the initial enzyme concentration, while the concentration of HRP in HRPloaded vesicles was $0.2 \mathrm{mg} \mathrm{mL}^{-1}$, equivalent to an encapsulation efficiency of about $10 \%$. All these values were determined in the presence of $\mathrm{PPOH}$ after an UV exposure time of $600 \mathrm{~s}$. Since the presence of additives, either in the mixture with free enzyme or coencapsulated into vesicles, did not significantly affect the enzyme activity, we also assumed that there is no influence on the enzyme encapsulation efficiency; therefore, we considered 
the same enzyme concentration values for all experiments comprising the enzyme/trehaloseloaded polymersomes.

\section{Up-concentration of polymersome dispersion}

The polymersome dispersion was concentrated through the polyethersulfone membranes (7.5 kDa MWCO) of Sartorius Vivapore 10/20 static concentrators (Sartorius Stedim Biotech GmbH, Germany). The container of each concentrator was filled up with $10 \mathrm{~mL}$ polymersome dispersion, and the 25-fold concentration level was reached in $90 \mathrm{~min}$. The up-concentrated dispersions were afterwards collected from the reservoirs and used for the digestion experiments with proteinase $\mathrm{K}$.

\section{Enzymatic activity}

Lac was assayed for activity using an ABTS solution with a concentration of $0.05 \mathrm{mM}$ in 50 $\mathrm{mM}$ sodium acetate buffer at $\mathrm{pH} 4.6$ and $\mathrm{RT}$. All measurements were performed by $\mathrm{UV}-\mathrm{Vis}$ spectroscopy at $414 \mathrm{~nm}$ and RT, using $1 \mathrm{~cm}$ quartz cuvettes. The absorbance was recorded every $1 \mathrm{~min}$ for each sample. First, the instrument was blanked with a mixture of $500 \mu \mathrm{L}$ buffer and $500 \mu \mathrm{L}$ substrate (ABTS) solutions. The assays were carried out by adding 500 $\mu \mathrm{L}$ of substrate solution to $500 \mu \mathrm{L}$ of Lac-loaded or Lac/additive-loaded vesicle dispersions. The activity of HRP encapsulated within polymersomes was determined with the ABTS assay as previously described ${ }^{29}$.

The enzyme activity was calculated in enzymatic units (U) per litre (L) with equation (1):

$$
\text { Enzyme Activity }\left(U L^{-1}\right)=\frac{\Delta A \cdot V_{f}}{\varepsilon \cdot d \cdot V_{S}}
$$

where $\Delta \mathrm{A}$ is the change in absorption at $414 \mathrm{~nm}\left[\mathrm{~min}^{-1}\right] ; \varepsilon$ is the extinction coefficient of ABTS at $414 \mathrm{~nm}\left[36000 \mathrm{M}^{-1} \mathrm{~cm}^{-1}\right] ; \mathrm{d}$ is the light path $[\mathrm{cm}] ; \mathrm{V}_{\mathrm{f}}$ is the final assay volume $[\mathrm{mL}] ; \mathrm{V}_{\mathrm{s}}$ is the volume of solution containing the enzyme [mL] added to ABTS solution. 
The reported activities were calculated as mean values of triplicate experiments, the error bars indicating the standard deviation.

\section{Digestion of laccase with proteinase $\mathrm{K}$}

$500 \mu \mathrm{L}$ of proteinase $\mathrm{K}$ solution $\left(200 \mu \mathrm{g} \mathrm{mL}^{-1}\right)$ in $50 \mathrm{mM}$ Tris/ $\mathrm{HCl}$ buffer $(\mathrm{pH} 8.0)$ containing $3 \mathrm{mM} \mathrm{CaCl} 2$ were added to $500 \mu \mathrm{L}$ of 25 -fold up-concentrated free enzyme solution or enzyme-loaded polymersome dispersions. The reaction mixtures were incubated at $37{ }^{\circ} \mathrm{C}$ for $24 \mathrm{~h}$, and then the $\mathrm{pH}$ value was adjusted back to 4.6 before measuring the enzyme activity. The Lac activity was calculated as described above.

\section{Thermal stability of free or encapsulated laccase in aqueous solution}

$1 \mathrm{~mL}$ solution of free Lac or Lac-loaded polymersome dispersion without sugar stabilizers was incubated inside of a heating oven for $6 \mathrm{~h}$, while the selected oven temperature was set between $40{ }^{\circ} \mathrm{C}$ and $80{ }^{\circ} \mathrm{C}$. After cooling down to RT, all samples were stored at $4{ }^{\circ} \mathrm{C}$ until the enzyme activity was measured as mentioned above. Enzyme activity was also expressed as residual activity, calculated using equation (2), which considers the activities of both heated and untreated samples:

$$
\text { Residual activity }(\%)=\frac{\text { Activity of heated sample }}{\text { Activity of untreated sample }} \times 100
$$

\section{Stability of free or encapsulated enzyme in dehydrated state}

The isolation of polymer vesicles using lyophilization was not taken into consideration since it can disrupt the polymersome architecture. Instead, polymersomes were dried by slow evaporation of water from the vesicle dispersions in air, at RT, to evaluate their stability in the dried state on a solid surface. To this end, $1 \mathrm{~mL}$ solution of free Lac $\left(0.36 \mathrm{mg} \mathrm{mL}^{-1}\right)$ or Lac-loaded vesicle dispersion, both prepared in $50 \mathrm{mM}$ sodium acetate buffer, $\mathrm{pH} 4.6$, was brought into a glass Petri dish, and then water was slowly removed by evaporation at RT. 
The dryness of powder-like samples was checked up until a constant weight has been reached. Both free and encapsulated enzyme samples were kept in dried state for 6 days at RT; afterwards, each sample was rehydrated with $1 \mathrm{~mL}$ of MilliQ water. To investigate the long-term stability of Lac in desiccated state, the enzyme activity was also measured after 20 days and 2 months, respectively.

The stability of enzyme/trehalose-loaded polymersomes, free enzyme or free enzyme/trehalose mixtures in dehydrated state was additionally evaluated after 3 weeks of storage at $50{ }^{\circ} \mathrm{C}$ inside of a heating oven, considering also HRP as another enzyme for these experiments, in comparison to Lac. The Lac and HRP activity were measured as described above.

\section{Effect of additives on enzyme stability}

The effect of glycerol, mannose and trehalose on the stability of free Lac and polymersomeencapsulated Lac against drying was tested, the additive concentrations ranging from $0.5 \mathrm{mg}$ $\mathrm{mL}^{-1}$ to $10 \mathrm{mg} \mathrm{mL}^{-1}$. In the case of HRP, only the effect of trehalose $\left(10 \mathrm{mg} \mathrm{mL}^{-1}\right)$ was investigated. $1 \mathrm{~mL}$ enzyme/additive-loaded vesicle dispersion was poured into a glass Petri dish, and then the solvent was evaporated at RT. $1 \mathrm{~mL}$ of a solution containing free enzyme $\left(0.36 \mathrm{mg} \mathrm{mL}^{-1}\right)$ and additive (same concentration as used for the preparation of the vesicles) were also dried in the same way. All samples were kept in dried state for 6 days at RT, and rehydrated with $1 \mathrm{~mL}$ of MilliQ water. The enzymatic activity was evaluated at RT as described above.

\section{Determination of trehalose content of polymersomes}

Cross-linked trehalose-containing nanoreactors dispersed in $50 \mathrm{mM}$ sodium acetate buffer (pH 4.6) were introduced into an ultrasonic bath (T460H, Bioblock Scientific, Germany) for 
20 min in order to break the vesicular structures and thus, to disrupt the polymersome membrane and release the content of their cavity. The trehalose concentration was evaluated by UV-Vis spectroscopy using a commercially available trehalose quantification assay (Megazyme International Ireland Ltd.) according to the manufacturer's protocol. The spectrophotometric assay involved the hydrolysis of trehalose into D-glucose by trehalase, followed by the conversion of D-glucose and ATP to glucose-6-phosphate (G-6-P) and ADP with hexokinase. The third step is a dehydrogenase-catalyzed conversion of G-6-P and $\mathrm{NADP}+$ to gluconate-6-phosphate and NADPH, which was followed at $340 \mathrm{~nm}$. The amount of NADPH formed during this reaction is stoichiometric to twice the amount of trehalose in the sample. The concentration of trehalose was calculated according to equation (3):

$$
c=\frac{V_{f} \cdot M}{2 \cdot \varepsilon \cdot d \cdot V_{s}} \cdot \Delta A_{\text {trehalose }}
$$

where $\mathrm{V}_{\mathrm{f}}$ is the final assay volume $[\mathrm{mL}] ; \mathrm{M}$ is the molar weight of trehalose $\left[\mathrm{g} \mathrm{mol}^{-1}\right] ; \varepsilon$ is the extinction coefficient of NADPH at $340 \mathrm{~nm}\left[6300 \mathrm{M}^{-1} \mathrm{~cm}^{-1}\right]$; $d$ is the light path [cm]; $\mathrm{V}_{\mathrm{s}}$ is the sample volume $[\mathrm{mL}] ; \Delta \mathrm{A}_{\text {trehalose }}$ is the difference in absorbance at $340 \mathrm{~nm}$ for both blank and sample.

The concentration of trehalose encapsulated within polymersomes was also indirectly determined by measuring the concentration of trehalose (with the assay described above) in the second fraction collected during the SEC purification step, which contains the nonencapsulated free enzyme and free trehalose. The encapsulated trehalose concentration was calculated as the difference between the initial trehalose concentration during vesicle formation and the concentration of non-encapsulated trehalose.

\section{Decolourisation studies}


Three synthetic dyes (Orange G, Toluidine Blue $\mathrm{O}$ and Indigo) were selected as model dyes to study the bleaching ability of Lac-loaded vesicles. Stock solutions of each dye were prepared in MilliQ water at concentrations of $0.2 \mathrm{mg} \mathrm{mL}^{-1}$ and stored in the dark at RT. Experiments were performed in $5 \mathrm{~mL}$ glass vials. The reaction mixture, containing $500 \mu \mathrm{L}$ dye solution, $500 \mu \mathrm{L}$ dispersion of nanoreactors, and $3 \mathrm{~mL}$ sodium acetate buffer $(50 \mathrm{mM}$, $\mathrm{pH}$ 4.6) was incubated in the dark at $50{ }^{\circ} \mathrm{C}$ and $90 \mathrm{rpm}$ for $6 \mathrm{~h}$. Decolourisation was determined by the decrease in absorbance at the characteristic wavelength of each dye ( $\lambda_{\max }$ $=476 \mathrm{~nm}$ for Orange $\mathrm{G}, 630 \mathrm{~nm}$ for Toluidine Blue $\mathrm{O}$, and $460 \mathrm{~nm}$ for Indigo). The decolourisation efficiency (DE) was calculated using equation (4):

$$
D E(\%)=\frac{A_{i}-A_{t}}{A_{i}} \cdot 100
$$

where $A_{i}$ is the initial absorbance of dye at $\lambda_{\max }$ and $A_{t}$ is the absorbance at $\lambda_{\max }$ of the dye after $6 \mathrm{~h}$ reaction time.

\section{Methods}

${ }^{1} \mathrm{H}-\mathrm{NMR}$ spectra were recorded on a Bruker DPX-400 spectrometer in $\mathrm{CDCl}_{3}$ and processed with MestReNova software. A GPCmax/TDA 305 system from Viscotek, Malvern, was used for characterization of copolymers by SEC. THF with a flow rate of $1.0 \mathrm{~mL} \mathrm{~min}^{-1}$ was used as eluent and the molecular weight distributions of copolymers were calibrated against nearly monodisperse polystyrene standards. The size of extruded nanoreactors with or without encapsulated additives was investigated by static and dynamic light scattering (SLS-DLS). The measurements of serial dilutions with polymer concentrations ranging from 0.0625 up to $0.5 \mathrm{mg} \mathrm{mL}^{-1}$ were performed on an ALV goniometer (Langen, Germany) that was equipped with an He-Ne laser $(\lambda=632.8 \mathrm{~nm})$. The samples were filtered through hydrophilic Millex-LH syringe filters (PTFE, $0.45 \mu \mathrm{m}$ pore size; Merck Millipore, 
Germany) into $10 \mathrm{~mm}$ cylindrical quartz cells, then placed into the measuring chamber, previously thermostated at $20^{\circ} \mathrm{C}$, and then measured at angles between $30^{\circ}$ and $150^{\circ}$ with an angular step of $10^{\circ}$. The photon intensity autocorrelation function g2(t) was determined using an ALV-7004/USB correlator. The apparent hydrodynamic radius $\left(\mathrm{R}_{\mathrm{h}}\right)$ from DLS (cumulant analysis) and the radius of gyration $\left(\mathrm{R}_{\mathrm{g}}\right)$ from SLS (Guinier analysis) were calculated according to the conventional methods ${ }^{52,53}$. Transmission electron microscopy (TEM) micrographs were acquired on a Philips EM400 electron microscope that was operated at $80 \mathrm{kV}$. Polymersome dispersions were deposited on a carbon-coated copper grid and negatively stained with $2 \%$ uranyl acetate solution. UV-Vis measurements were performed on a Specord 210 Plus spectrophotometer (Analytik Jena, Germany) using $1 \mathrm{~cm}$ quartz cuvettes (Hellma).

\section{RESULTS AND DISCUSSION}

\section{Formation of enzyme-loaded polymersome nanoreactors}

Lac-loaded polymersomes were prepared by the self-assembly of bifunctional acrylateterminated A-PMOXA- $b$-PDMS- $b$-PMOXA-A triblock copolymers in sodium acetate buffer (pH 4.6) containing $2 \mathrm{mg} \mathrm{mL}^{-1}$ Lac using the film rehydration method ${ }^{54}$. To remove the excess of free enzyme, the polymersomes were purified by two successive steps, first SEC, followed by dialysis.

A bifunctional acrylate-terminated PMOXA- $b$-PDMS- $b$-PMOXA triblock copolymer was selected because its end groups can be easily cross-linked to improve the stability of the polymer membrane. Cross-linked polymersomes have enhanced mechanical properties towards shear forces or pressure-induced stress, which appears, for example, during upconcentration of vesicle solutions. Moreover, cross-linked vesicles are more resistant against 
surfactant-induced membrane disruption and are more stable in a variety of solvents ${ }^{34}$. To achieve the cross-linking of polymer chain end groups in the polymersome membrane and to make the membrane of the polymersomes semipermeable for organic molecules, the vesicles were mixed with PPOH and irradiated with UV light. According to our previous study, reaction of polymersomes with $1 \mathrm{mg} \mathrm{mL}^{-1} \mathrm{PPOH}$ under UV irradiation for $30 \mathrm{~s}$ induces the permeabilization of polymersome membrane, without leading to a substantial formation of cross-linked polymers ${ }^{29}$. Consequently, the reaction mixtures were irradiated longer, and the conversion of vinyl end groups and PPOH was investigated by ${ }^{1} \mathrm{H}-\mathrm{NMR}$ spectroscopy in the absence of both enzymes and additives (Fig. 2, Fig. S3 and Fig. S4).
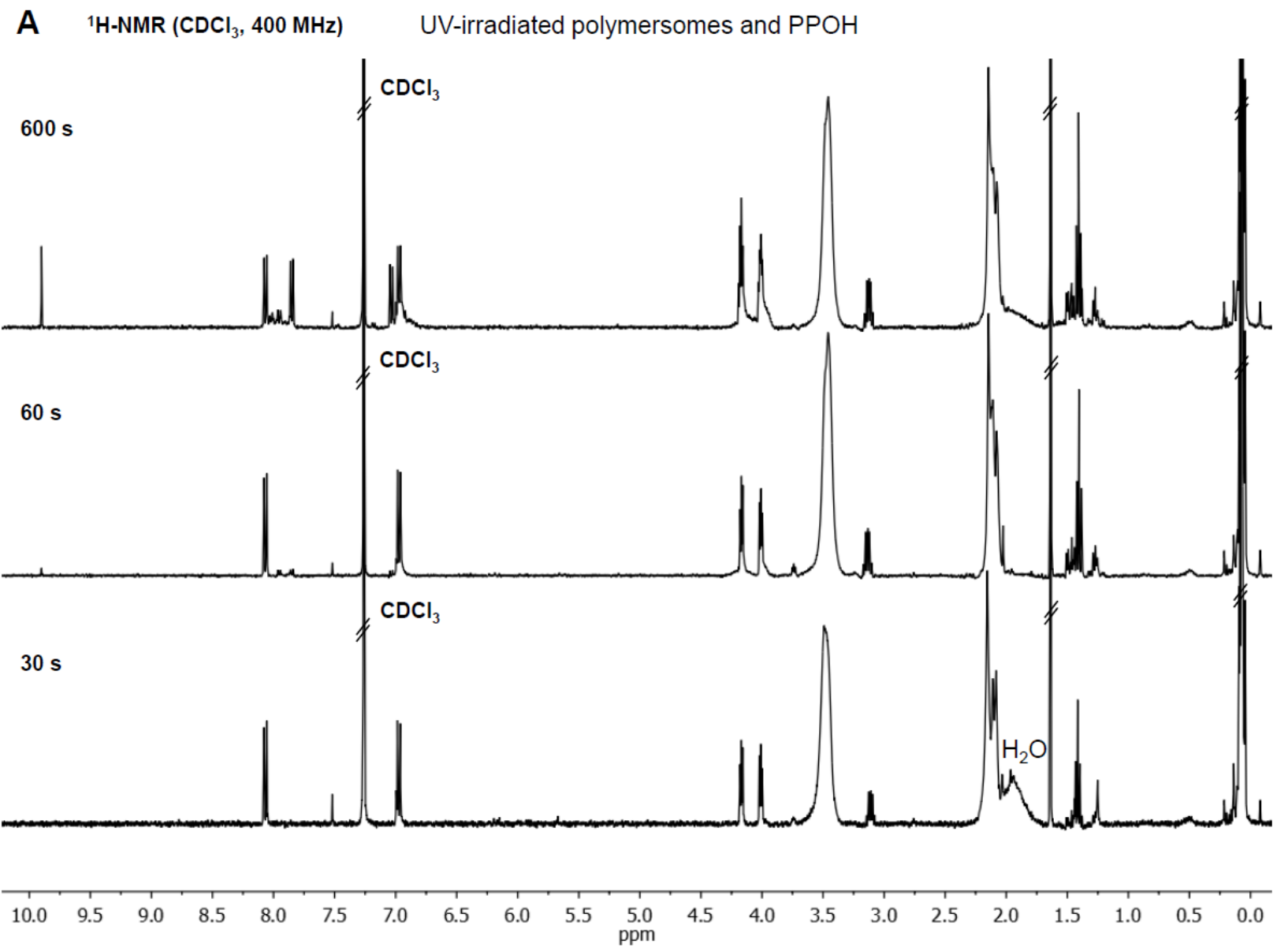


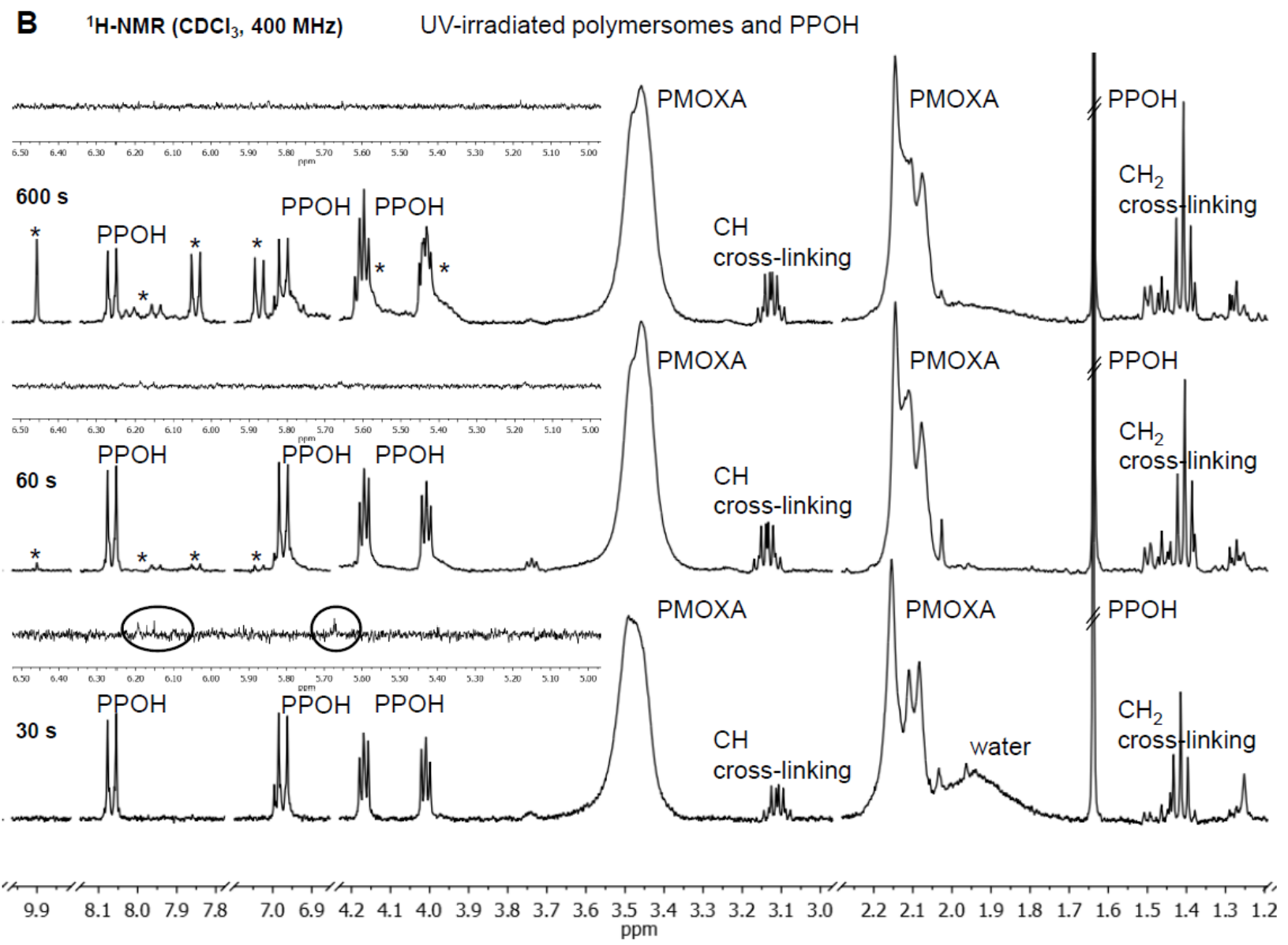

Fig. $2 .{ }^{1} \mathrm{H}$-NMR spectra of A-PMOXA- $b$-PDMS- $b$-PMOXA-A triblock copolymer after the UV irradiation of polymersome aqueous dispersions for $30 \mathrm{~s}, 60 \mathrm{~s}$, and $600 \mathrm{~s}$ in the presence of PPOH (A). Sections from the ${ }^{1} \mathrm{H}-\mathrm{NMR}$ spectra showing the changes in proton signals for the $\mathrm{PPOH} /$ polymersome mixture over the selected irradiation times (B).

The peaks corresponding to the vinyl protons are still visible in the presence of $\mathrm{PPOH}$ after $30 \mathrm{~s}$ of UV irradiation (about $25 \%$ unreacted vinyl groups), are barely visible after $60 \mathrm{~s}$ and disappeared within $600 \mathrm{~s} \mathrm{("zoom-in} \mathrm{panels"} \mathrm{in} \mathrm{Fig.} \mathrm{2B).} \mathrm{Thus,} \mathrm{the} \mathrm{UV} \mathrm{irradiation} \mathrm{for} 600 \mathrm{~s}$ in the presence of $\mathrm{PPOH}$ ensured the complete conversion of vinyl end groups of copolymers and, therefore, led to cross-linked vesicles. 
After the photoreaction with $\mathrm{PPOH}$, the samples were dialyzed again to remove the unreacted PPOH. However, the characteristic peaks of the photo-reagent are still visible in the spectra, regardless of the irradiation time (Fig. 2A; see also Fig. S2 for the $\mathrm{PPOH}$ spectrum). Most likely, some of the PPOH was entrapped into the polymersomes and did not photodegrade within the chosen irradiation time. Nevertheless, additional peaks indicate benzoyl radicals as intermediate species of vinyl polymerisation (Fig. 2B). The proton signals of 4-(2-hydroxyethoxy) benzaldehyde at $9.90 \mathrm{ppm}$ (as singlet), $7.85 \mathrm{ppm}$, and 7.03 ppm (as doublets) became more intense as the UV irradiation proceeded. Moreover, the small peaks arising after $600 \mathrm{~s}$ irradiation in the $8.05-7.90 \mathrm{ppm}$ range, and the 'shoulders' in the 7.0-6.9 ppm and 4.2-3.9 ppm regions point out for aromatic PPOH fragments bound to the copolymers. Therefore, it is apparent that benzoyl radicals are responsible for the initiation of cross-linking reaction.

As a control reaction to show that $\mathrm{PPOH}$ was necessary to induce crosslinking and permeabilization (vide infra), polymersomes were also irradiated with UV light for up to $900 \mathrm{~s}$ in the absence of the photo-reagent. According to the ${ }^{1} \mathrm{H}-\mathrm{NMR}$ spectra, the double bonds were not consumed (Fig. S4). Specifically, an UV irradiation for $600 \mathrm{~s}$ in the absence of $\mathrm{PPOH}$ did not significantly affect the vinyl groups, whereas after $900 \mathrm{~s}$ about $12 \%$ of them were cross-linked ("zoom-in panels" in Fig. S4).

The morphology of self-assembled structures in the presence or absence of PPOH was investigated by light scattering (Table 1 and Fig. S5A) as well as TEM (Fig. 3 and Fig. S5B). 
Table 1. Light scattering data for Lac-filled polymersomes before and after UV irradiation in the presence of $\mathrm{PPOH}$.

\begin{tabular}{lrccc}
\hline Lac-filled polymersomes & \multicolumn{1}{c}{$R_{g}{ }^{\mathrm{a}}[\mathrm{nm}]$} & $R_{h}{ }^{\mathrm{b}}[\mathrm{nm}]$ & $\rho=R_{g} / R_{h}$ & $P D I^{\mathrm{b}}$ \\
\hline Before irradiation & $85 \pm 4$ & $94 \pm 3$ & 0.90 & 0.243 \\
After 30 s of irradiation, w/ PPOH & $88 \pm 3$ & $90 \pm 2$ & 0.92 & 0.247 \\
After 600 s of irradiation, w/ PPOH & $105 \pm 4$ & $108 \pm 5$ & 0.97 & 0.229 \\
\hline
\end{tabular}

${ }^{a}$ Determined from SLS; ${ }^{b}$ Derived from DLS.
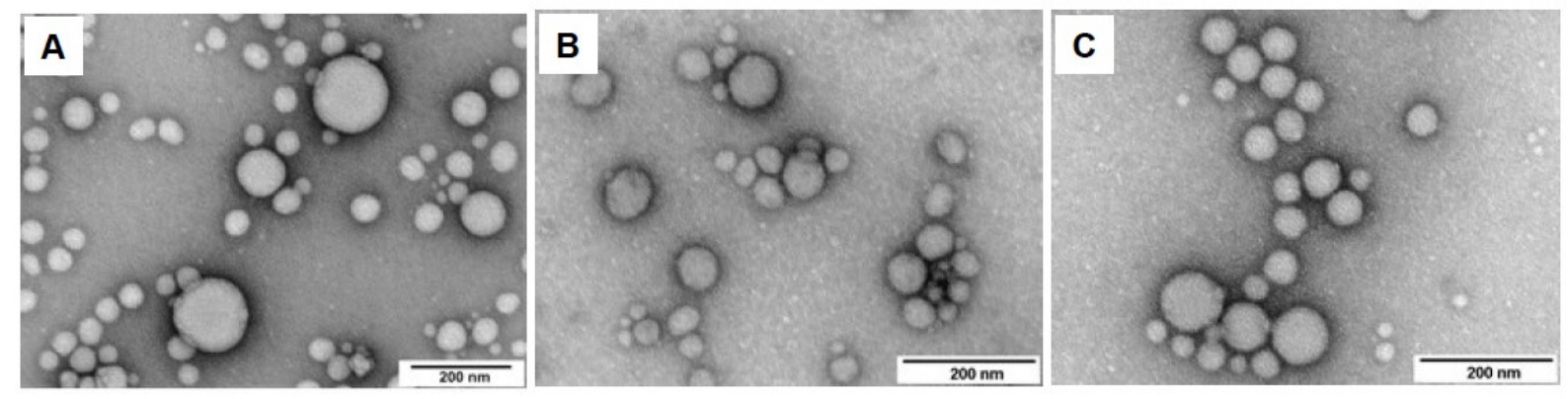

Fig. 3. TEM micrographs of A-PMOXA- $b$-PDMS- $b$-PMOXA-A nanoreactors encapsulating Lac: before irradiation (A), after $30 \mathrm{~s}$ irradiation in the presence of PPOH (B), and after 600 $\mathrm{s}$ irradiation in the presence of $\mathrm{PPOH}(\mathrm{C})$.

DLS measurements allow determining the $R_{h}$ values, while the value of $R_{g}$ can be obtained from the SLS data. The objects have radii of gyration between 85 and $105 \mathrm{~nm}$. The ratio of the two radii, i.e. the $\rho$-parameter $\left(\rho=\mathrm{R}_{\mathrm{g}} / \mathrm{R}_{\mathrm{h}}\right)$ ranges from 0.90 to 0.97 , indicating the presence of vesicles ${ }^{52,53,55}$. While crosslinking seems to slightly enlarge the polymersomes, their vesicular structure is preserved and is neither affected by the UV exposure or the reaction with $\mathrm{PPOH}$ (Table 1).

TEM micrographs show mainly spherical objects with radii between 40 and $90 \mathrm{~nm}$, but also the presence of smaller structures, possibly micelles, before and after UV exposure in the 
presence of $\mathrm{PPOH}$ (Fig. 3). Therefore, the size and morphology of Lac-loaded polymersomes were not affected by photoreaction with $\mathrm{PPOH}$. The observation that nanoparticles appear smaller in TEM than in light scattering is often made and can be attributed to the osmotic shrinkage on the TEM grid during staining and washing ${ }^{56-58}$, or the exposure to vacuum and electron beam during TEM image acquisition ${ }^{59}$.

To prove that photo-cross-linking stabilized the polymersome membrane, samples were concentrated 25 times using solvent absorption concentrators. Polymersomes are the preferred self-assembled morphology when the block copolymers are prepared in dilute solution. If the polymer concentration is increased, the dilute regime of the water/polymer binary phase diagram is left, and consequently, other self-assembled morphologies are preferred $^{60}$. As a result, the polymersomes would break and release the encapsulated Lac. In this context, the stability of polymersomes can be indirectly assessed with digestion experiments, because free Lac is susceptible to enzymatic degradation, while Lac within polymersomes is protected against protease $\mathrm{s}^{30}$. Proteinase $\mathrm{K}$, an enzyme which cleaves peptide bonds with a broad specificity, was added to 25-times-concentrated solutions of Lac-filled polymersomes that had been irradiated for $30 \mathrm{~s}$ or $600 \mathrm{~s}$ in the presence of $\mathrm{PPOH}$. For comparison, the protease was also added to a solution of non-encapsulated Lac. Then, the samples were incubated at $37{ }^{\circ} \mathrm{C}$ for $24 \mathrm{~h}$. The activity of Lac before and after the digestion with protease was measured with the ABTS assay (Fig. S6). Proteinase K completely inactivated the free laccase, as expected (Fig. S6A). Lac fully retained its activity when encapsulated within polymersomes that were cross-linked by UV irradiation for $600 \mathrm{~s}$ (Fig. S6B). In contrast, the nanoreactors that had been irradiated for $30 \mathrm{~s}$ lost more than $50 \%$ of their activity (Fig. S6A). These results allow us to conclude that the cross- 
linking of polymersome membrane by irradiation for $600 \mathrm{~s}$ in the presence of $\mathrm{PPOH}$ yielded stable polymersomes that can withstand up-concentration, whereas an UV exposure for just $30 \mathrm{~s}$ was not sufficient to fully stabilize the polymersomes against membrane disruption at higher polymer concentrations.

To demonstrate that the membrane of polymersomes became permeable upon the treatment with $\mathrm{PPOH}$, enzymatic activity assays were performed with Lac-encapsulating polymersomes, using ABTS as substrate (Fig. S7). Lac-filled polymer vesicles that were irradiated by UV light in the absence of PPOH did not catalyse the colorimetric reaction, which indicates that their membrane was not permeable for the substrate. In contrast, $\mathrm{PPOH}-$ treated nanoreactors converted the substrate to its blue-green coloured form, monitored as an increase in absorbance at $414 \mathrm{~nm}$. The reaction rate was slightly higher for vesicles that were photoreacted with $\mathrm{PPOH}$ for $30 \mathrm{~s}$ than those that were irradiated for $600 \mathrm{~s}$. This difference could either be caused by differences in membrane permeability or in a partial deactivation of the enzyme upon long UV irradiation. Nevertheless, these results clearly demonstrate that polymersome nanoreactors with a semipermeable membrane could be obtained by reacting them with $\mathrm{PPOH}$ under UV light, which is in accordance with the photo-permeabilization reported in our previous studies ${ }^{29}$. In conclusion, as the photoreaction of polymersomes with $\mathrm{PPOH}$ for $600 \mathrm{~s}$ yielded stabilized and permeable polymersomes, this method for preparation of nanoreactors was chosen for further experiments unless otherwise stated.

Thermostability of laccase-loaded nanoreactors in solution without addition of stabilizing sugars 
The effect of encapsulation of Lac within polymersomes on the thermal stability of the enzyme was assessed by incubating dispersions of Lac-filled polymersomes for $6 \mathrm{~h}$ at different temperatures in the absence of lyoprotectant. Then, the enzymatic activity was determined with the ABTS assay at $25{ }^{\circ} \mathrm{C}$ (Fig. 4). For comparison, solutions of free Lac were treated accordingly.

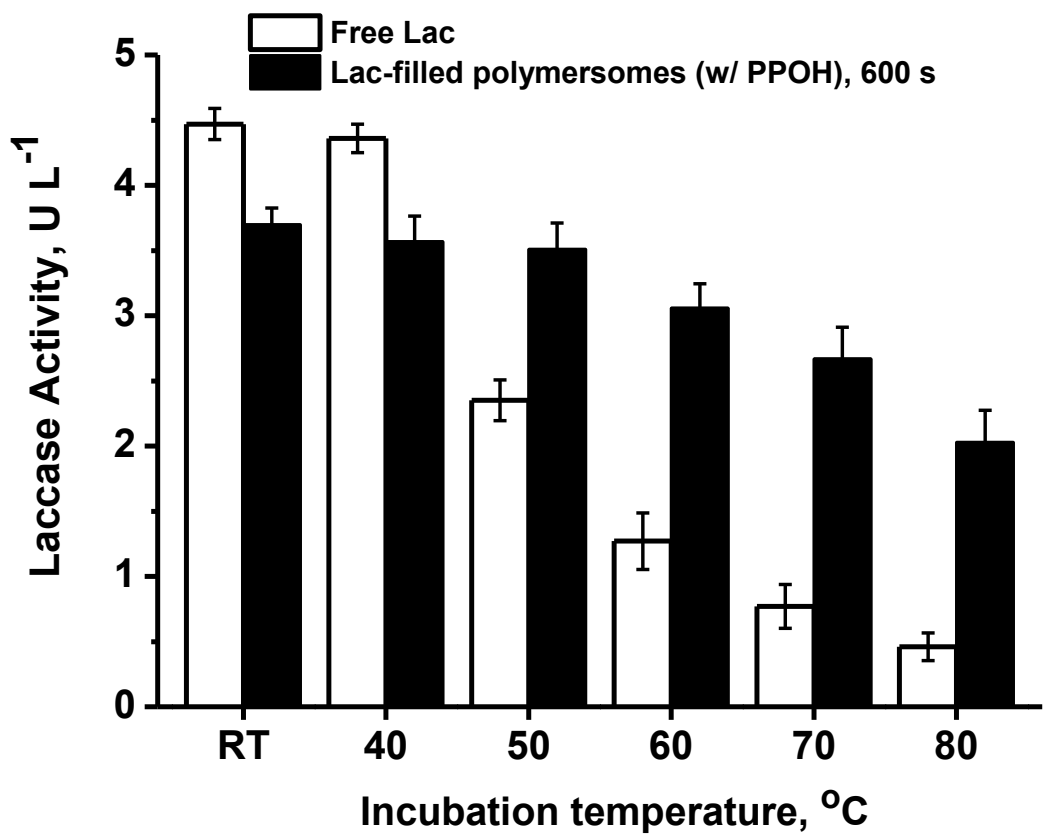

Fig. 4. Thermostability of Lac encapsulated within polymersomes in comparison to the free enzyme (in the absence of sugar stabilizers). The enzymatic activity was assessed with the ABTS assay at $25{ }^{\circ} \mathrm{C}$ and $\mathrm{pH} 4.6$ after incubating the vesicle dispersions or free enzyme solutions for $6 \mathrm{~h}$ at elevated temperatures.

The encapsulation of Lac into cross-linked polymersomes improved the thermostability of the enzyme, particularly at higher temperatures (Fig. 4, and Fig. S8). After $6 \mathrm{~h}$ of incubation at $50{ }^{\circ} \mathrm{C}$, the cross-linked nanoreactors retained nearly full activity, while the free Lac lost half of its initial activity. At a temperature of $80{ }^{\circ} \mathrm{C}$, the residual activity of Lac 
encapsulated within the cross-linked polymersomes was reduced to about $55 \%$, while only $12 \%$ of the activity remained for the free Lac.

The microenvironment within the inner cavity of vesicles helped to maintain the structure of enzymes, probably by stabilizing their structure through non-covalent interactions with the hydrophilic leaflet of the polymersome membrane. Furthermore, by encapsulating an enzyme within a confined space, the probability to interact with other enzyme molecules is lowered, and therefore, the risk that enzyme molecules irreversibly aggregate is reduced.

\section{Co-encapsulation of laccase and stabilizing additives}

Polymersome nanoreactors are usually studied and applied in aqueous solution $20,21,27,31,49$, because drying of the nanoreactors in the absence of any stabilizers can disassemble or damage them. However, for many applications dry nanoreactor formulations would be desirable, since powders are easier to handle, more compact (lighter) to transport and store than liquids. Since lyophilization is often used in preparation of pharmaceutical formulations, lyoprotectant molecules have been added to polymersome solutions before the start of freeze-drying to avoid the mechanical stress onto the polymer membrane, to increase the long-term stability of lyophilized polymer vesicles upon storage and to improve their redispersion in aqueous media ${ }^{38,61}$. Stabilizing additives might significantly enhance the stability of the enzymes under long-term storage in dehydrated state or under heat exposure when co-encapsulated with the enzymes into polymersomes. Therefore, trehalose was coencapsulated together with Lac into polymersomes during the self-assembly of copolymers by adding a defined concentration of trehalose to the enzyme solution used for vesicle formation. All non-encapsulated trehalose and enzyme was removed from the vesicles by a combination of SEC and dialysis. 
To determine the efficiency of trehalose encapsulation, the SEC fraction that contained the polymersomes was analysed with a colorimetric assay for trehalose. To this end, polymer vesicles that were prepared in $10 \mathrm{mg} \mathrm{mL}^{-1}$ trehalose solution were broken by ultrasonication for a period of $20 \mathrm{~min}$ after their purification and cross-linking. The concentration of trehalose was measured to be $0.91 \mathrm{mg} \mathrm{mL}^{-1}$ in the SEC fraction. Thus, the trehalose encapsulation efficiency was about $9 \%$ (Table S1). Interestingly, the assay did not detect trehalose when the polymersome fraction was not ultrasonicated (Table S1). Hence, trehalose was contained exclusively within the polymersomes and apparently did not leach out during the purification, permeabilization/stabilization and analysis steps. This was further confirmed by the observation that the buffer recovered after dialysis did not contain any trehalose (Table S1). The trehalose content of the polymersomes was also determined indirectly by measuring the concentration of free trehalose that was collected during the SEC purification step and comparing it to the initial concentration of trehalose in the liquid used for vesicle formation. According to this method, the vesicle fraction contained $0.92 \mathrm{mg}$ $\mathrm{mL}^{-1}$ trehalose (Table S1), which correlates well with the direct measurement of trehalose concentration in the polymersome dispersion. It is likely that most of the trehalose is located within the vesicle lumen and that some of it is physically bound to the hydrophilic leaflets of the polymersome membrane.

To investigate the effect of trehalose encapsulation on the stability of polymersomes upon drying, the cross-linked Lac/trehalose-filled polymersomes were characterized by TEM and LS after desiccation, storage in the dry state for 6 days at RT and rehydration (Fig. 5 and Table 2). 

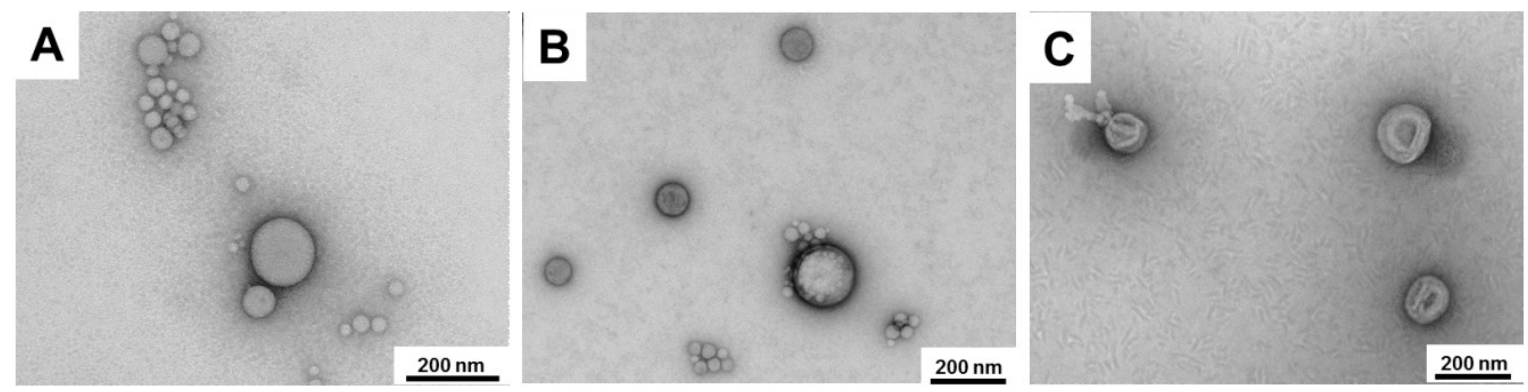

Fig. 5. TEM micrographs of cross-linked Lac/trehalose-filled polymersomes that were desiccated in air at RT, stored in the dry state for 6 days and rehydrated. The polymersomes were formed by co-encapsulation of trehalose at concentrations of $0.5 \mathrm{mg} \mathrm{mL}^{-1}$ (A), $5 \mathrm{mg}$ $\mathrm{mL}^{-1}(\mathrm{~B})$, and $10 \mathrm{mg} \mathrm{mL}^{-1}(\mathrm{C})$.

Table 2. Light scattering data for cross-linked Lac/trehalose-filled polymersomes that were desiccated in air at RT, stored in the dry state for 6 days and rehydrated.

\begin{tabular}{ccccc}
\hline $\begin{array}{l}\text { Initial trehalose concentration } \\
{\left[\mathrm{mg} \mathrm{mL}^{-1}\right]}\end{array}$ & $R_{g}{ }^{\mathrm{a}}[\mathrm{nm}]$ & $R_{h}{ }^{\mathrm{b}}[\mathrm{nm}]$ & $\rho=R_{g} / R_{h}$ & $P D I^{\mathrm{b}}$ \\
\hline 0.5 & $93 \pm 3$ & $95 \pm 2$ & 0.97 & 0.192 \\
5 & $89 \pm 5$ & $96 \pm 4$ & 0.93 & 0.217 \\
10 & $101 \pm 4$ & $107 \pm 5$ & 0.94 & 0.221 \\
\hline
\end{tabular}

${ }^{\mathrm{a}}$ Determined from SLS; ${ }^{\mathrm{b}}$ Derived from DLS.

The nanostructures have radii of gyration between 90 and $100 \mathrm{~nm}$, and their $\rho$-factor is close to 1.0 for all samples, indicating the presence of vesicular structures (Table 2). TEM images also show the typical spherical nano-objects (Fig. 5). Even storage of the dry formulations for 3 weeks at $50{ }^{\circ} \mathrm{C}$ did not affect the size and morphology of the polymersomes (Fig. S9 and Table S2). Thus, the polymersomes survived the drying and rehydration processes when trehalose was co-encapsulated into the vesicles. In contrast, Lac-filled polymersomes that lacked trehalose aggregated upon desiccation and could not be fully rehydrated in water. The ability of trehalose to prevent aggregation of polymersomes might be due to the 
presence of trehalose molecules within the hydrophilic outer leaflets of the block copolymer membrane. Trehalose molecules are also able to interact with the hydrophilic PMOXA blocks owing to their hydrogen-bond acceptor amide groups, and consequently, a small amount of trehalose can be entrapped in between the inner as well as the outer PMOXA chains during the self-assembly of amphiphilic block copolymers. A comparable observation was made for lipid bilayers, where trehalose stabilized the liposome membrane against aggregation via the formation of hydrogen bonds between the $\mathrm{OH}$ groups of trehalose and the polar headgroups of lipids ${ }^{61}$.

\section{Effect of desiccation on Lac activity}

The effect of drying on the activity of Lac within the polymersome nanoreactors was studied. Samples were dried at RT, kept on the shelf for 6 days in the dry state, rehydrated with MilliQ water and then assayed for their enzymatic activity (Fig. 6).

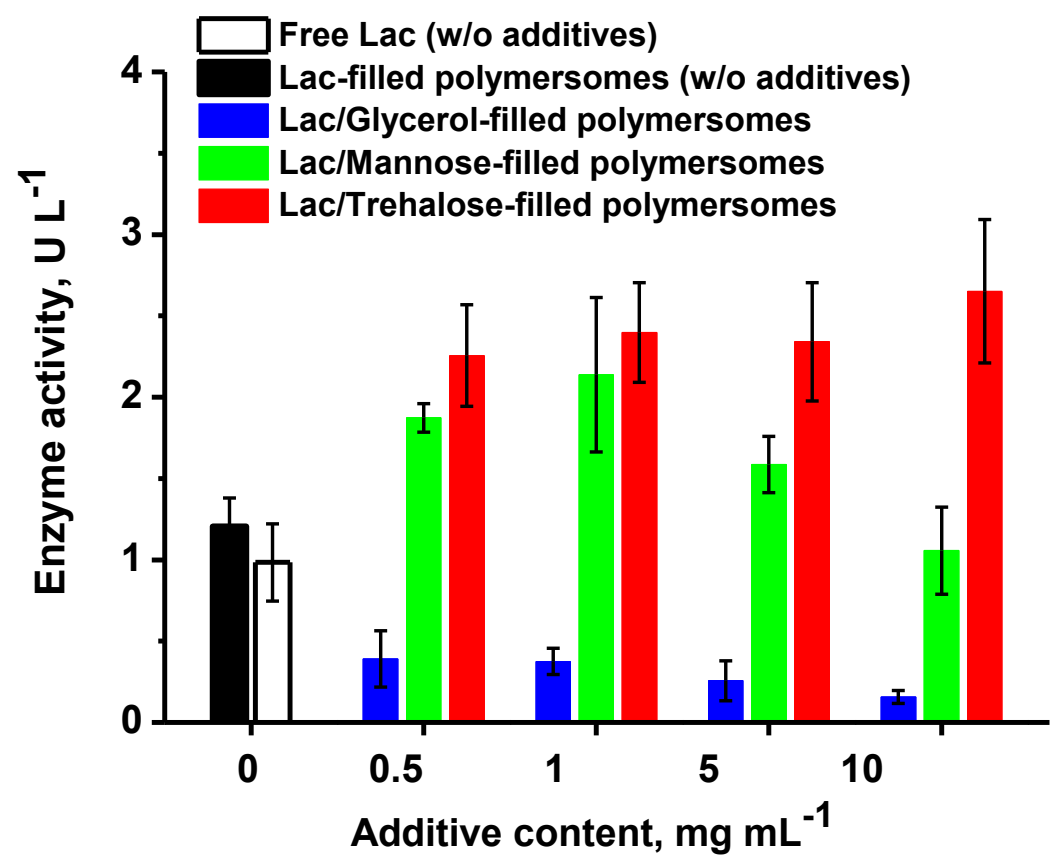


Fig. 6. Enzymatic activities of cross-linked Lac-filled polymersomes and Lac coencapsulated with glycerol, mannose, or trehalose within cross-linked polymersomes after 6 days of desiccation and subsequent rehydration compared to free Lac.

Free Lac and Lac within cross-linked polymersomes that did not contain any additives retained an activity of about 0.98 and $1.21 \mathrm{U} \mathrm{L}^{-1}$ respectively, which corresponds to $23 \%$ and $32 \%$ of their original activity (Table S3). Thus, the activities of free and encapsulated Lac drastically decreased after desiccation, and the vesicles alone could not prevent this deactivation. In contrast, when trehalose was present in the vesicles, the encapsulated Lac retained an activity of up to $2.65 \mathrm{U} \mathrm{L}^{-1}$ (77\% of its original activity, Figure 6 and Table S3). The stabilization effect slightly increased with increasing trehalose content. Consequently, trehalose stabilized the encapsulated enzyme. A trehalose concentration of $10 \mathrm{mg} \mathrm{mL}^{-1}$ during vesicle formation was chosen for the preparation of nanoreactors in subsequent experiments. For comparison, other possible stabilizing additives (glycerol and mannose) were also co-encapsulated with laccase in the same way and at the same concentrations as trehalose. Glycerol failed to protect the enzyme against desiccation and even deactivated it further (Fig. 6). Co-encapsulation of the enzyme with mannose resulted in a stabilization that was similar with that of trehalose at an additive concentration of 0.5 and $1 \mathrm{mg} \mathrm{mL}^{-1}$. However, at higher mannose concentrations, the stabilization decreased. Thus, trehalose was the most efficient stabilizing agent. These results correlate well with previous reports that found trehalose to be an exceptionally good protective agent, prolonging the life-time of proteins $^{62,63}, \mathrm{DNA}^{64}$, liposomes ${ }^{65}$, and even cells ${ }^{66-68}$ in the dry state. The non-reducing 
disaccharide stabilizes and preserves the structure of proteins because the glass transition temperature of trehalose is high enough $\left(\sim 116^{\circ} \mathrm{C}\right)$ to vitrify the dry protein formulations ${ }^{69}$. Since these results show that trehalose can protect the encapsulated and desiccated Lac during short-term storage, long-term stability studies for up to 2 months were performed (Fig. 7).

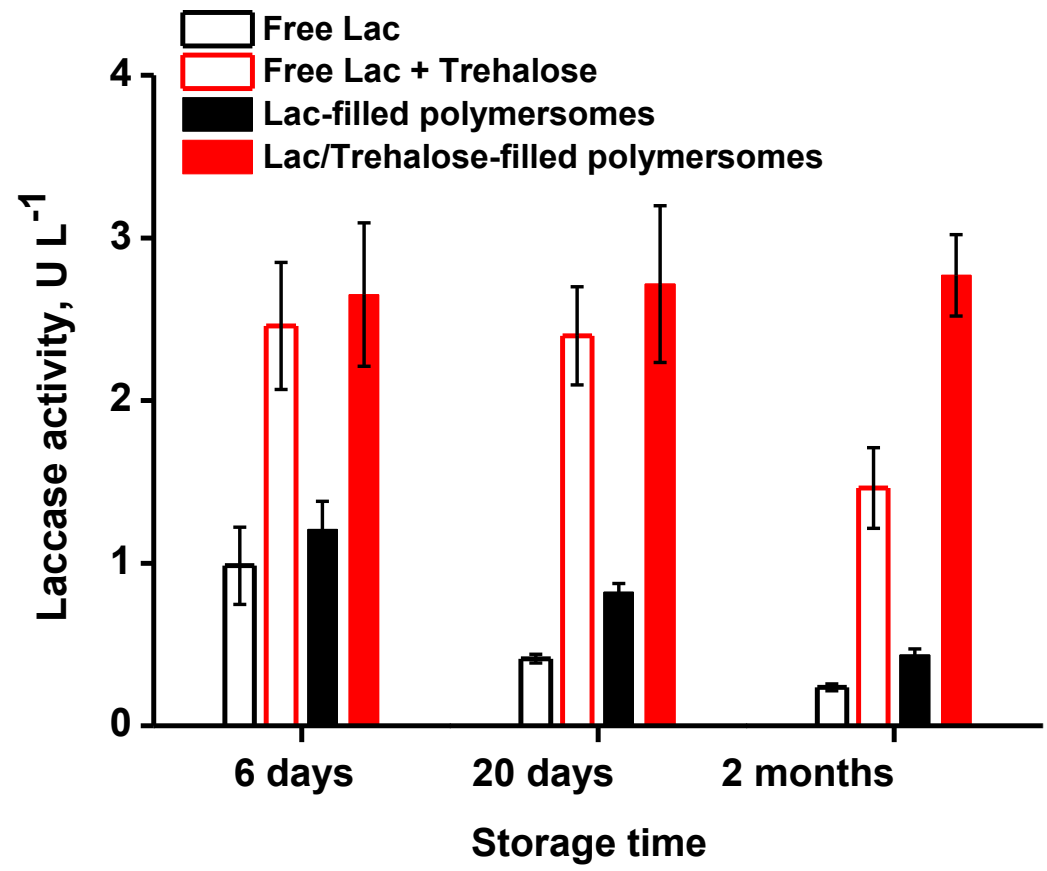

Fig. 7. Enzymatic activities of cross-linked Lac-filled polymersomes and Lac coencapsulated with trehalose within cross-linked polymersomes in comparison to free Lac, after long-term storage in dry state. All samples were kept in desiccated state at RT for 6 days, 20 days, and 2 months, and were then rehydrated with Milli-Q water. The initial concentration of trehalose was $10 \mathrm{mg} \mathrm{mL}^{-1}$, and the enzyme activity was evaluated with the ABTS assay.

Dried cross-linked Lac/trehalose-filled polymersomes exhibited an activity of $2.77 \mathrm{U} \mathrm{L}^{-1}$ throughout the whole experiment (after 2 months of storage in dry state), which corresponds 
to approx. $81 \%$ of their initial activity. The stability of Lac-filled polymersomes that did not contain trehalose and the stability of free Lac in the presence and absence of trehalose were also evaluated for comparison. Free Lac retained its enzymatic activity up to 20 days of storage in dry state when mixed with trehalose $\left(2.40 \mathrm{U} \mathrm{L}^{-1}\right.$, and $65 \%$, respectively), but its activity significantly drops down to about $1.46 \mathrm{U} \mathrm{L}^{-1}$ (39\%) when stored for longer periods of time (2 months).

Moreover, the key role of trehalose in enzyme protection is more evident when Lac was maintained in desiccated state in the absence of this additive. The enzymatic activity decreasing continuously to about $11.5 \%$ of its initial activity for Lac-loaded vesicles and to $5.5 \%$ for the free Lac after 2 months. These results clearly confirm the stabilizing effect of trehalose and, in addition, indicate that the protective effect is enhanced when the enzyme and disaccharide are co-encapsulated within the confined space of polymer vesicles. A similar beneficial influence has been previously reported in the case of trehalose-containing glycopolymers, which better preserved lysozyme activity compared to trehalose alone, when the enzyme was lyophilized or stored at elevated temperatures, and then rehydrated ${ }^{70}$. In this particular case, the entropic barrier created by organizing the carbohydrate moieties of glycopolymers around the protein play the major protecting role when the enzyme is exposed to extreme temperatures. In a similar manner, the cross-linked membrane of our polymersomes apparently takes over the task of keeping the trehalose molecules in an organized arrangement around Lac.

\section{Stabilization of peroxidase with trehalose in polymersome nanoreactors}

Encouraged by the stabilization of Lac within polymersomes, the effect of trehalose on the stability of another enzyme, i.e. HRP, was also tested. HRP and trehalose (initial 
concentration of $10 \mathrm{mg} \mathrm{mL}^{-1}$ ) were co-encapsulated to form polymersome nanoreactors, which were successively dried at RT and then stressed by exposure to a heat burden of 50 ${ }^{\circ} \mathrm{C}$ for 3 weeks. For comparison, Lac/trehalose-filled polymersomes were treated in a similar manner. After cooling down to RT, the polymer vesicles co-encapsulating the enzyme and trehalose were rehydrated with MilliQ water, and then the enzyme activity was measured. Fig. 8 plots residual activities, i.e. enzyme activity after incubation at elevated temperatures normalized to the enzymatic activity before heating (see Fig. S10, for the absolute data).

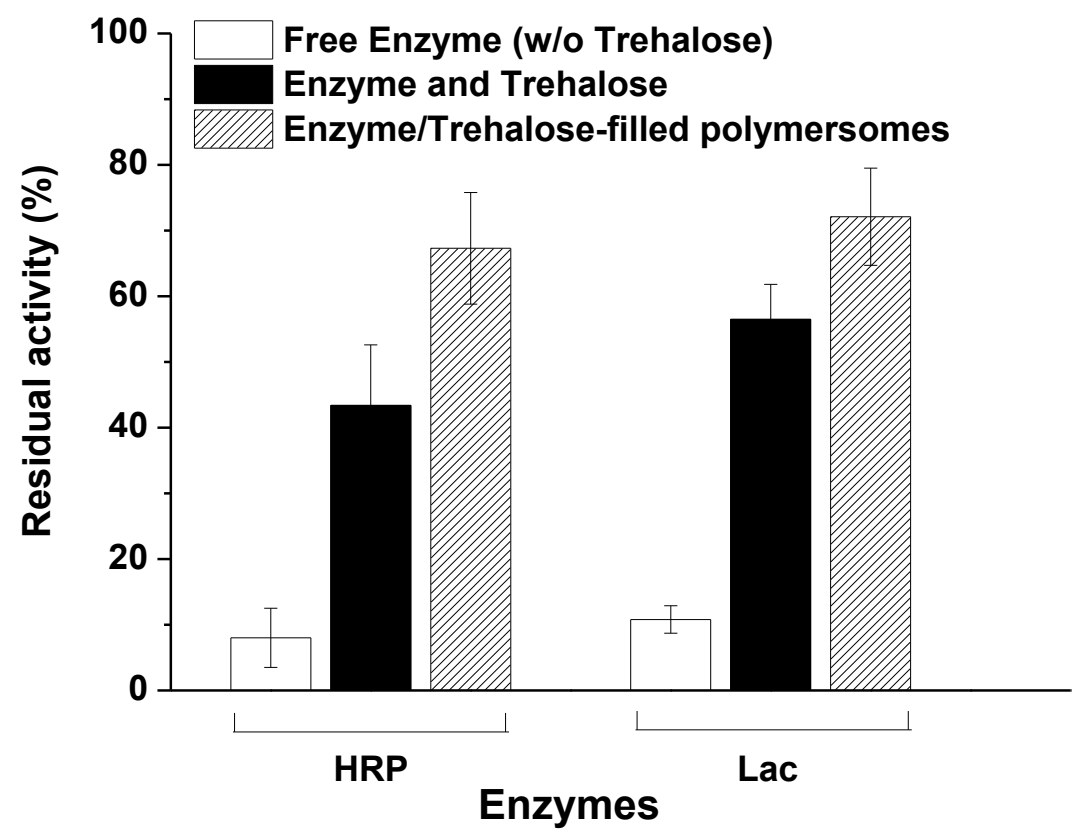

Fig. 8. Thermostability of free or co-encapsulated enzymes (either HRP or Lac) in trehalosefilled polymersomes, shown as residual activity, after desiccation, storage for 21 days in dry state at $50{ }^{\circ} \mathrm{C}$ and subsequent rehydration in MilliQ water, compared to free enzymes. The initial trehalose concentration was $10 \mathrm{mg} \mathrm{mL}^{-1}$.

As expected, trehalose stabilized HRP as it does with Lac. HRP within polymersomes retained $67 \%$ of its initial activity when it was in contact with trehalose, whereas free HRP 
retained only $8 \%$ of its activity under similar conditions. Trehalose stabilized free HRP to $43 \%$ of its original activity. Thus, the residual activity of trehalose-stabilized free HRP remained well below the value of HRP that was co-encapsulated with trehalose.

The results presented herein allowed us to conclude that trehalose-based stabilization of enzymes within polymersomes is not limited to Lac, but does also work with other enzymes.

\section{Decolourisation of textile dyes}

To prove the utility of Lac/trehalose-filled nanoreactors in reactions that are relevant for applications where elevated temperatures are required, their catalytic activity in oxidation of three textile dyes Orange $\mathrm{G}$, Toluidine Blue $\mathrm{O}$ and Indigo was evaluated in aqueous solution. These reactions were also carried out, for comparison, with the same amount of free $\mathrm{Lac}\left(0.36 \mathrm{mg} \mathrm{mL}^{-1}\right)$ and with the polymersomes containing the enzyme but lacking trehalose. Since the Lac-filled nanoreactors showed almost a constant enzymatic activity up to $50{ }^{\circ} \mathrm{C}$ during the thermostability studies in solution (vide supra), this temperature was further selected to perform the decolourisation reactions. After a contact time of $6 \mathrm{~h}$, the cross-linked nanoreactors containing Lac co-encapsulated with trehalose catalysed the decolourisation of Orange G, Toluidine Blue $\mathrm{O}$ and Indigo dyes with conversions of $42 \%$, $61 \%$ and $75 \%$, respectively (Table S4), whilst in the absence of trehalose, the conversions of dyes into their colourless forms were of $38 \%, 56 \%$ and $68 \%$, respectively. The presence of trehalose inside of polymersomes does therefore not have a negative influence on the ability of enzyme to catalyse the decolourisation reactions. However, free Lac resulted in much lower conversions (decolourisation efficiencies ranging from $16 \%$ for Orange $\mathrm{G}$ to $21 \%$ for Indigo). Thus, the Lac-filled polymersomes were more efficient in decolourisation of dyes than the free enzyme under these conditions, despite the fact that the polymersome 
membrane represents an additional diffusion barrier for the substrates. Most probably, the polymersomes protected the enzyme from thermal denaturation, while the Lac became partial inactivated when it was free in solution. This observation is in accordance with the results of the thermostability tests described above.

\section{CONCLUSIONS}

Two enzymes, laccase and horseradish peroxidase were successfully encapsulated during the self-assembly process of bifunctional acrylate-terminated PMOXA- $b$-PDMS- $b$-PMOXA triblock copolymers. It was found that co-encapsulation of trehalose with enzymes into polymersomes is a beneficial strategy to stabilize and protect the protein functionality in dehydrated state (Lac) or under heat (Lac and HRP). Enzyme-containing systems with a long shelf-life, good activity and an enhanced stability in extreme conditions, such as high temperatures, should extend the use of biocatalysis into industrial applications. In addition, the membrane stabilization by cross-linking approach allows the formation of shape persistent vesicles, which can be concentrated without vesicle disruption and protect laccase against proteolytic attack. Moreover, the encapsulated trehalose allowed to dry and rehydrate the vesicles and stabilized the encapsulated enzyme. In the same time, the laccase/trehalose-filled polymersomes showed a high efficiency when they were used as biocatalysts in the oxidation of some textile dyes (Orange G, Toluidine Blue $\mathrm{O}$ and Indigo dyes). Nanoreactors stabilizing and protecting enzymes have a great potential for a wide range of applications, such as cosmetics, biosensing, environmentally friendly oxidation, or bleaching technologies.

Supplementary Information: ${ }^{1} \mathrm{H}-\mathrm{NMR}$ spectra, DLS-SLS data, TEM micrographs, enzymatic activity assays, thermostability of Lac encapsulated within polymersomes in 
comparison to the free enzyme, the trehalose spectrophotometric assay, and decolorization data.

\section{Conflicts of interest}

There are no conflicts to declare.

\section{Acknowledgements}

The KTI/CTI (now Innosuisse, Grant. No. 12980.1PFNM-NM), the Swiss National Science Foundation (Grant No. 150059, PP00P2_144697, and PP00P2_172927), the National Centre of Competence in Research NCCR Molecular Systems Engineering (51NF4O_141825), and the University of Basel are acknowledged for financial support. The authors gratefully thank Gabriele Persy for the TEM measurements, whereas I.A.D. acknowledges Dario Rossini for the guidance and help on using Adobe Illustrator and Adobe Photoshop for creating the graphics of this manuscript.

\section{Notes}

M.V.D. and I.A.D. mention that their contribution to this manuscript, and all the corresponding data included herein, was accomplished during their PostDoc fellowships at the University of Basel.

\section{REFERENCES}

1. Moreno, A. D.; Ibarra, D.; Eugenio, M. E.; Tomás- Pejó, E. Laccases as Versatile Enzymes: From Industrial Uses to Novel Applications. Chem. Technol. Biotechnol. 2020, 95, 481-494.

2. Singh, G.; Arya, S. K. Utility of Laccase in Pulp and Paper Industry: A Progressive Step Towards the Green Technology. Int. J. Biol. Macromol. 2019, 134, 1070-1084.

3. Singh, R. L.; Singh, P. K.; Singh, R. P. Enzymatic Decolorization and Degradation of Azo Dyes - A Review. Int. Biodeterior. Biodegr. 2015, 104, 21-31.

4. Ghosh, B.; Saha, R.; Bhattacharya, D.; Mukhopadhyay, M. Laccase and its Source of Sustainability in an Enzymatic Biofuel Cell. Biores. Technol. Rep. 2019, 6, 268-278.

5. Rodríguez-Delgado, M. M.; Alemán-Nava, G. S.; Rodríguez-Delgado, J. M.; DieckAssad, G.; Martínez-Chapa, S. O.; Barceló, D.; Parra, R. Laccase-Based Biosensors for Detection of Phenolic Compounds. Trends Anal. Chem. 2015, 74, 21-45. 
6. Zheng, Y.; Wang, D.; Li, Z.; Sun, X.; Gao, T.; Zhou, G. Laccase Biosensor Fabricated on Flower-Shaped Yolk-Shell $\mathrm{SiO}_{2}$ Nanospheres for Catechol Detection. Colloids Surf. A 2018, 538, 202-209.

7. Wang, W. Lyophilization and Development of Solid Protein Pharmaceuticals. Int. J. Pharm. 2000, 203, 1-60.

8. Kamerzell, T. J.; Esfandiary, R.; Joshi, S. B.; Middaugh, C. R.; Volkin, D. B. Protein-Excipient Interactions: Mechanisms and Biophysical Characterization Applied to Protein Formulation Development. Adv. Drug Deliv. Rev. 2011, 63, 11181159.

9. James, S.; McManus, J. J. Thermal and Solution Stability of Lysozyme in the Presence of Sucrose, Glucose, and Trehalose. J. Phys. Chem. B 2012, 116, 1018210188.

10. Chapman, R.; Stenzel, M. H. All Wrapped up: Stabilization of Enzymes within Single Enzyme Nanoparticles. J. Am. Chem. Soc. 2019, 141, 2754-2769.

11. Wei, Q.; Xu, M.; Liao, C.; Wu, Q.; Liu, M.; Zhang, Y.; Wu, C.; Cheng, L.; Wang, Q. Printable Hybrid Hydrogel by Dual Enzymatic Polymerization with Superactivity. Chem. Sci. 2016, 7, 2748-2752.

12. Gupta, M. N.; Perwez, M.; Sardar, M. Protein crosslinking: Uses in chemistry, biology and biotechnology. Biocatal. Biotransfor. 2020, 38, 178-201.

13. Wahab, R. A., Elias, N.; Abdullah, F.; Ghoshal, S. K. On the taught new tricks of enzymes immobilization: An all-inclusive overview. React. Funct. Polym. 2020, 152, 104613.

14. Savolainen, A.; Zhang, Y.; Rochefort, D.; Holopainen, U.; Erho, T.; Virtanen, J.; Smolander, M. Printing of Polymer Microcapsules for Enzyme Immobilization on Paper Substrate. Biomacromolecules 2011, 12, 2008-2015.

15. Li, Y.; Wu, H.; Su, Z. Enzyme-based Hybrid Nanoflowers with High Performances for Biocatalytic, Biomedical, and Environmental Applications. Coord. Chem. Rev. 2020, 416, 213342.

16. Rideau, E.; Dimova, R.; Schwille, P.; Wurm, F. R.; Landfester, K. Liposomes and Polymersomes: A Comparative Review Towards Cell Mimicking. Chem. Soc. Rev. 2018, 47, 8572-8610.

17. Thamboo, S.; Najer, A.; Belluati, A.; von Planta, C.; Wu, D.; Craciun, I.; Meier, W.; Palivan, C. G. Mimicking Cellular Signaling Pathways within Synthetic Multicompartment Vesicles with Triggered Enzyme Activity and Induced Ion Channel Recruitment. Adv. Funct. Mater. 2019, 29, 1904267.

18. Gaitzsch, J.; Appelhans, D.; Wang, L.; Battaglia, G.; Voit, B. Synthetic Bionanoreactor: Mechanical and Chemical Control of Polymersome Membrane Permeability. Angew Chem Int Ed. 2012, 51, 4448-4451.

19. Varlas, S.; Blackman, L. D.; Findlay, H. E.; Reading, E.; Booth, P. J.; Gibson, M. I.; O'Reilly, R. K. Photoinitiated Polymerization-Induced Self-Assembly in the Presence of Surfactants Enables Membrane Protein Incorporation into Vesicles. Macromolecules 2018, 51, 6190-6201.

20. Contini, C.; Pearson, R.; Wang, L.; Messager, L.; Gaitzsch, J.; Rizzello, L.; RuizPerez, L.; Battaglia, G. Bottom-Up Evolution of Vesicles from Disks to High-Genus Polymersomes. iScience 2018, 7, 132-144. 
21. Lebleu, C.; Rodrigues, L.; Guigner, J.-M.; Brûlet, A.; Garanger, E.; Lecommandoux, S. Self-Assembly of PEG- b- PTMC Copolymers: Micelles and Polymersomes Size Control. Langmuir 2019, 35, 13364-13374.

22. Grazon, C.; Salas-Ambrosio, P.; Ibarboure, E.; Buol, A.; Garanger, E.; Grinstaff, M. W.; Lecommandoux, S.; Bonduelle, C. Aqueous Ring-Opening PolymerizationInduced Self-Assembly (ROPISA) of N-carboxyanhydrides. Angew. Chem. Int. Edit. 2020, 59, 622-626.

23. Rikken, R. S. M.; Engelkamp, H.; Nolte, R. J. M.; Maan, J. C.; van Hest, J. C. M.; Wilson, D. A.; Christianen, P. C. M. Shaping Polymersomes into Predictable Morphologies via Out-Of-Equilibrium Self-Assembly. Nat. Commun. 2016, 7, 12606.

24. Che, H.; de Windt, L. N. J.; Zhu, J.; Pijpers, I. A. B.; Mason, A. F.; Abdelmohsen, L. K. E. A.; van Hest, J. C. M. Pathway Dependent Shape-Transformation of AzideDecorated Polymersomes. Chem. Commun. 2020, 56, 2127-2130.

25. Gaitzsch, J.; Huang, X.; Voit, B. Engineering Functional Polymer Capsules toward Smart Nanoreactors. Chem. Rev. 2016, 116, 1053-1093.

26. Varlas, S.; Foster, J. C.; Georgiou, P. G.; Keogh, R.; Husband, J. T.; Williams, D. S.; O'Reilly, R. K. Tuning the Membrane Permeability of Polymersome Nanoreactors Developed by Aqueous Emulsion Polymerization-Induced Self-Assembly. Nanoscale 2019, 11, 12643-12654.

27. Che, H.; van Hest, J. C. M. Adaptive Polymersome Nanoreactors. Chem. Nano Mat. 2019, 5, 1-19.

28. Kuiper, S. M.; Nallani, M.; Vriezema, D. M.; Cornelissen, J. J. L. M.; van Hest, J. C. M.; Nolte, R. J. M.; Rowan, A. E. Enzymes Containing Porous Polymersomes as Nano Reaction Vessels for Cascade Reactions. Org. Biomol. Chem. 2008, 6, 43154318.

29. Spulber, M.; Najer, A.; Winkelbach, K.; Glaied, O.; Waser, M.; Pieles, U.; Meier, W.; Bruns, N. Photoreaction Of A Hydroxyalkyphenone with the Membrane of Polymersomes: A Versatile Method to Generate Semipermeable Nanoreactors. J. Am. Chem. Soc. 2013, 135, 9204-9212.

30. Spulber, M.; Baumann, P.; Saxer, S. S.; Pieles, U.; Meier, W.; Bruns, N. Poly(NVinylpyrrolidone)-Poly(Dimethylsiloxane)-Based Polymersome Nanoreactors for Laccase-Catalyzed Biotransformations. Biomacromolecules 2014, 15, 1469-1475.

31. Dinu, M. V.; Spulber, M.; Renggli, K.; Wu, D.; Monnier, C. A.; Petri-Fink, A.; Bruns, N. Filling Polymersomes with Polymers by Peroxidase-Catalyzed Atom Transfer Radical Polymerization. Macromol. Rapid Commun. 2015, 36, 507-514.

32. Peters, R. J. R. W.; Marguet, M.; Marais, S.; Fraaije, M. W.; van Hest, J. C. M.; Lecommandoux, S. Cascade Reactions in Multicompartmentalized Polymersomes. Angew. Chem. Int. Ed. 2014, 53, 146-150.

33. Katz, J. S.; Levine, D. H.; Davis, K. P.; Bates, F. S.; Hammer, D. A.; Burdick, J. A. Membrane Stabilization of Biodegradable Polymersomes. Langmuir 2009, 25, 44294434.

34. Nardin, C.; Hirt, T.; Leukel, J.; Meier, W. Polymerized ABA Triblock Copolymer Vesicles. Langmuir 2000, 16, 1035-1041. 
35. Holzer, M.; Vogel, V.; Mäntele, W.; Schwartz, D.; Haase, W.; Langer, K. PhysicoChemical Characterisation of PLGA Nanoparticles after Freeze-Drying and Storage. Eur. J. Pharm. Biopharm. 2009, 72, 428-437.

36. Kelly, J. M.; Pearce, E. E.; Martin, D. R.; Byrne, M. E. Lyoprotectants Modify and Stabilize Self-Assembly o Polymersomes. Polymer 2016, 87, 316-322.

37. Ayen, W. Y.; Kumar, N. A Systematic Study on Lyophilization Process of Polymersomes for Long-Term Storage Using Doxorubicin-Loaded (PEG) ${ }_{3}$-PLA Nanopolymersomes. Eur. J. Pharm. Sci. 2012, 46, 405-414.

38. Ccorahua, R.; Moreno, S.; Gumz, H.; Sahre, K.; Voit, B.; Appelhans, D. Reconstitution Properties of Biologically Active Polymersomes after Cryogenic Freezing and a Freeze-Drying Process. RSC Adv. 2018, 8, 25436-25443.

39. Westh P.; Ramløv, H. Trehalose Accumulation in the Tardigrade Adorybiotus Coronifer During Anhydrobiosis. J. Exp. Zool. 1991, 258, 303-311.

40. Hengherr, S.; Heyer, A. G.; Köhler, H.-R.; Schill, R. O. Trehalose and Anhydrobiosis in Tardigrades-Evidence for Divergence in Responses to Dehydration. FEBS J. 2008, 275, 281-288.

41. Jönsson, K. I.; Rabbow, E.; Schill, R. O.; Harms-Ringdahl, M.; Rettberg, P. Tardigrades Survive Exposure to Space in Low Earth Orbit. Curr. Biol. 2008, 18, R729.

42. Allison, S. D.; Chang, B.; Randolph, T. W.; Carpenter, J. F. Hydrogen Bonding Between Sugar and Protein Is Responsible for Inhibition of Dehydration-Induced Protein Unfolding. Arch. Biochem. Biophys. 1999, 365, 289-298.

43. Massari, A. M.; Finkelstein, I. J.; McClain, B. L.; Goj, A.; Wen, X.; Bren, K. L.; Loring, R. F.; Fayer, M. D. The Influence of Aqueous versus Glassy Solvents on Protein Dynamics: Vibrational Echo Experiments and Molecular Dynamics Simulations. J. Am. Chem. Soc. 2005, 127, 14279-14289.

44. Bellavia, G.; Paccou, L.; Guinet, Y.; Hédoux, A. How Does Glycerol Enhance the Bioprotective Properties of Trehalose? Insight From Protein-Solvent Dynamics. $J$. Phys. Chem. B 2014, 118, 8928-8934.

45. Moiset, G.; López, C. A.; Bartelds, R.; Syga, L.; Rijpkema, E.; Cukkemane, A.; Baldus, M.; Poolman, B.; Marrink, S. J. Disaccharides Impact the Lateral Organization of Lipid Membranes. J. Am. Chem. Soc. 2014, 136, 16167-16175.

46. Wilkop, T. E.; Sanborn, J.; Oliver, A. E.; Hanson, J. M.; Parikh, A. N. On-Demand Self-Assembly of Supported Membranes Using Sacrificial, Anhydrobiotic Sugar Coats. J. Am. Chem. Soc. 2014, 136, 60-63.

47. Paul, S.; Paul, S. Molecular Insights Into the Role of Aqueous Trehalose Solution on Temperature-Induced Protein Denaturation. J. Phys. Chem. B 2015, 119, 1598-1610.

48. Tonnis, W. F.; Mensink, M. A.; de Jager, A.; van der Voort Maarschalk, K.; Frijlink, H. W.; Hinrichs, W. L. J. Size and Molecular Flexibility of Sugars Determine the Storage Stability of Freeze-Dried Proteins. Mol. Pharm. 2015, 12, 684-694.

49. Baumann, P.; Spulber, M.; Dinu, I. A.; Palivan, C. G. Cellular Trojan Horse Based Polymer Nanoreactors with Light-Sensitive Activity. J. Phys. Chem. B 2014, 118, 9361-9370.

50. Dinu, I. A.; Duskey, J. T.; Car, A.; Palivan, C. G.; Meier, W. Engineered non-toxic cationic nanocarriers with photo-triggered slow-release properties. Polym. Chem. 2016, 7, 3451-3464. 
51. Xu, F.; Palmer, A. E.; Yaver, D. S.; Berka, R. M.; Gambetta, G. A.; Brown, S. H.; Solomon, E. I. Targeted Mutations in a Trametes Villosa Laccase Axial Perturbations of the T1 Copper J. Biol. Chem. 1999, 274, 12372-12375.

52. Burchard, W. Light Scattering Techniques, In Physical Techniques for the Study of Food Biopolymers; Ross-Murphy, S.B., Ed.; Blackie Academics and Professional: New York, NY, 1994; p. 151.

53. Burchard, W. Static and Dynamic Light Scattering from Branched Polymers and Biopolymers, In Light Scattering from Polymers; Springer: Berlin Heidelberg, 1983; p. 1.

54. Battaglia, G.; Ryan, A. J. Pathways of Polymeric Vesicle Formation. J. Phys. Chem. $B$ 2006, 110, 10272-10279.

55. Stauch, O.; Schubert, R.; Savin, G.; Burchard, W. Structure of Artificial Cytoskeleton Containing Liposomes in Aqueous Solution Studied by Static and Dynamic Light Scattering. Biomacromolecules 2002, 3, 565-578.

56. Habel, J.; Ogbonna, A.; Larsen, N.; Cherre, S.; Kynde, S.; Midtgaard, S. R.; Kinoshita, K.; Krabbe, S.; Jensen, G. V.; Hansen, J. S.; Almdal, K.; Helix-Nielsen, C. Selecting analytical tools for characterization of polymersomes in aqueous solution. $R S C A d v$. 2015, 5, 79924-79946.

57. Kumar, M.; Grzelakowski, M.; Zilles, J.; Clark, M.; Meier, W. Highly permeable polymeric membranes based on the incorporation of the functional water channel protein Aquaporin Z. Proc. Natl. Acad. Sci. 2007, 104, 20719-20724.

58. Carlsen, A.; Glaser, N.; Le Meins, J.-F.; Lecommandoux, S. Block Copolymer Vesicle Permeability Measured by Osmotic Swelling and Shrinking. Langmuir 2011, 27, 4884-4890.

59. Jung, K. Y.; Park, B. C.; Song, W. Y.; Ho, B.; Eom, T. B. Measurement of 100-nm Polystyrene Sphere by Transmission Electron Microscope Powder Technol. 2002, 126, 255-265.

60. Braun, J.; Bruns, N.; Pfohl, T.; Meier, W. Phase Behavior of Vesicle- Forming Block Copolymers in Aqueous Solutions. Macromol. Chem. Phys. 2011, 212, 12451254.

61. Crowe, J. H.; Crowe, L. M.; Chapman, D. Preservation of Membranes in Anhydrobiotic Organisms: The Role of Trehalose. Science 1984, 223, 701-703.

62. Paz-Alfaro, K. J.; Ruiz-Granados, Y. G.; Uribe-Carvajal, S.; Sampedro, J. G. Trehalose-Mediated Thermal Stabilization of Glucose Oxidase from Aspergillus Niger. J. Biotechnol. 2009, 141, 130-136.

63. Olsson, C.; Jansson, H.; Swenson, J. The Role of Trehalose for the Stabilization of Proteins. J. Phys. Chem. B 2016, 120, 4723-4731.

64. Zhang, M.; Oldenhof, H.; Sydykov, B.; Bigalk, J.; Sieme, H.; Wolkers, W. F. FreezeDrying of Mammalian Cells Using Trehalose: Preservation of DNA Integrity. Sci. Rep. 2017, 7, 6198.

65. Liu, J.; Chen, C.; Lu, C.; Li, W. Different mechanisms on the stabilization of POPC membrane by trehalose upon varied mechanical stress. J. Mol. Liq. 2019, 275, 839848.

66. Sun, M.; Jiang, M.; Cui, J.; Liu, W.; Yin, L.; Xu, C.; Wei, Q.; Yan, X.; Chen, F. A novel approach for the cryodesiccated preservation of tissue-engineered skin substitutes with trehalose. Mater. Sci. Eng. C 2016, 60, 60-66. 
67. Huang, H.; Zhao, G.; Zhang, Y.; Xu, J.; Toth, T. L.; He, X. Predehydration and Ice Seeding in the Presence of Trehalose Enable Cell Cryopreservation. ACS Biomater. Sci. Eng. 2017, 3, 1758-1768.

68. Stewart, S.; He, X. Intracellular Delivery of Trehalose for Cell Banking. Langmuir 2019, 35, 7414-7422.

69. Drake, A. C.; Lee, Y.; Burgess, E. M.; Karlsson, J. O. M.; Eroglu, A.; Higgins, A. Z. Effect of Water Content on the Glass Transition Temperature of Mixtures of Sugars, Polymers, and Penetrating Cryoprotectants in Physiological Buffer. PLoS One 2018, 13, e0190713.

70. Mancini, R. J.; Lee, J.; Maynard, H. D. Trehalose Glycopolymers for Stabilization of Protein Conjugates to Environmental Stressors. J. Am. Chem. Soc. 2012, 134, 84748479. 